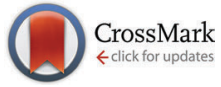

Cite this: J. Mater. Chem. C, 2016, 4, 4556

Received 13th February 2016, Accepted 5th April 2016

DOI: $10.1039 / \mathrm{c} 6 \mathrm{tc00639f}$

www.rsc.org/MaterialsC

\section{Synthetic control over intra- and intermolecular charge transfer can turn on the fluorescence emission of non-emissive coumarin $\dagger$}

\author{
Byung Hak Jhun, ${ }^{a}$ Kei Ohkubo, ${ }^{\text {bc }}$ Shunichi Fukuzumi*cd and Youngmin You*a
}

Conjugated molecules bearing carbonyl groups typically exhibit weak fluorescence emission due to the presence of a non-radiative $n-\pi^{\star}$ transition state. Strong fluorescence emission from $n-\pi^{\star}$ chromophores has been sought through the use of synthetic approaches that incorporate strong electron donors, such as amines, into the conjugated structures. As an alternative to these existing approaches, we investigated two charge-transfer strategies using a series of 1-benzopyran-2-one (coumarin) derivatives. The first strategy involved attaching chromophoric aryl moieties at the 7 position of coumarin. This molecular control produced two effects: the $n-\pi^{\star}$ transition state was destabilized and an intramolecular charge-transfer (ICT) state was generated. The photoluminescence quantum yields (PLQYs) of the bichromophoric dyads increased with the $\pi$-conjugation length of the aryl groups, and a PLQY as high as 0.80 was achieved. The second strategy facilitated exciplex fluorescence in poly( $N$-vinylcarbazole) (PVK) films within which coumarin derivatives have been molecularly dispersed. A thermodynamic analysis based on electrochemical data indicated that exciplex generation involved electron transfer from PVK to photoexcited coumarin molecules. Exciplex fluorescence was uniquely advantageous in its ability to tune the fluorescence emission color upon addition of electron donors having oxidation potentials less positive than that of PVK. Mechanistic studies, including femtosecond laser flash photolysis, were conducted to identify the molecular parameters that governed the two fluorescence properties. A mechanistic understanding may provide useful insights into the development of electrofluorescent materials that harness triplet as well as singlet excitons.

\section{Introduction}

A variety of fluorescent compounds have been developed based on the 1-benzopyran-2-one (coumarin) platform. ${ }^{1,2}$ This platform is non-fluorescent and provides a photoluminescence quantum yield (PLQY) below 0.001 in cyclohexane. ${ }^{3,4}$ The non-emissive properties of coumarin originate from the presence of a

\footnotetext{
${ }^{a}$ Division of Chemical Engineering and Materials Science,

Ewha Womans University, Seoul 03760, Korea. E-mail: odds2@ewha.ac.kr

${ }^{b}$ Department of Material and Life Science, Graduate School of Engineering, Osaka University, ALCA and SENTAN, Japan Science and Technology (JST), Suita, Osaka 565-0871, Japan. E-mail: fukuzumi@chem.eng.osaka-u.ac.jp

${ }^{c}$ Department of Chemistry and Nano Science, Ewha Womans University, Seoul 03760, Korea

${ }^{d}$ Faculty of Science and Engineering, Meijo University, ALCA and SENTAN, Japan Science and Technology Agency (JST), Nagoya, Aichi 468-0073, Japan

$\dagger$ Electronic supplementary information (ESI) available: Fig. S1-S18 display the predicted isodensity plot of the molecular orbitals, the Lippert-Mataga plot, cyclic and differential pulse voltammograms, UV-vis absorption spectra, photoluminescence spectra obtained at $78 \mathrm{~K}$, photoluminescence decay traces, transient absorption spectra, and copies of ${ }^{1} \mathrm{H}$ and ${ }^{13} \mathrm{C}$ NMR spectra; Tables S1 and S2 list the summary of the TD-DFT calculation results and the photophysical data for PMMA films doped with the coumarin compounds. See DOI: 10.1039/c6tc00639f
}

carbonyl moiety. The photophysical mechanism by which carbonyl groups quench fluorescence emission remains an intensive research subject. Previous studies provided evidence that the $n-\pi^{*}$ transition in the carbonyl group plays a central role in quenching radiation through adiabatic relaxation, ${ }^{5}$ intersystem crossing, ${ }^{6}$ vibronic deactivation, $^{7}$ and irreversible ring opening of the lactone. ${ }^{7}$ Strong emission may be achieved by modifying coumarin to incorporate electron-donating groups, such as amino and hydroxyl groups. This modification facilitates strong charge separation, generating an emissive intramolecular charge-transfer (ICT) state. Synthetic modifications involve condensation reactions that require boiling temperatures and strong acids. Although recent advances have introduced significant versatility into the syntheses of modified coumarins, ${ }^{2,8-18}$ molecular libraries have not been fully developed. Furthermore, the amino and hydroxyl groups render the coumarin fluorescence emission extremely sensitive to substitution patterns and the rigidity and the Lewis acidity of the medium. ${ }^{19}$ Therefore, the development of versatile principles for harnessing fluorescence emission from a non-emissive coumarin backbone continues to pose significant challenges.

One potential approach to addressing this challenge may involve replacing the amino and hydroxyl groups with aryl units. 
Aromatic hydrocarbons with extended $\pi$ conjugation can donate electrons to the electron-deficient coumarin upon photoexcitation, promoting an ICT transition. Depending on the oxidation potentials of the aromatic units, the ICT transition state may be located below the $n-\pi^{*}$ transition state. Aromatic units with low band gap energies may align energetically with the coumarin levels to enable this radiative process. This ICT fluorescence is advantageous over the fluorescence produced by other coumarin derivatives bearing amino or hydroxyl groups. The fluorescence transition probability may be enhanced because the ICT transition state involves an allowed $\pi-\pi^{*}$ transition in the aromatic component. In addition, this strategy does not rely on the use of heteroatoms with lone-pair electrons, obviating the dependence of the fluorescence emission on the solvent medium. Facilitated ICT fluorescence is enabled by introducing aromatic units with judiciously controlled oxidation potentials and $\pi-\pi^{*}$ transition energies.

An alternative approach to harnessing the fluorescence emission of a non-emissive coumarin backbone involves enabling exciplex formation. Exciplexes are excited-state bimolecular complexes formed during excited-state electron transfer. ${ }^{20}$ The energy level of an exciplex, which is defined by the difference between the electrochemical potentials of an electron donor and an electron acceptor, is usually located below the excitonic states of the individual molecules. ${ }^{21,22}$ Exciplex fluorescence offers a viable strategy for harnessing the excited-state energy of the non-emissive $n-\pi^{*}$ transition state in coumarin. Previous studies have identified exciplex fluorescence in binary mixtures of semiconducting polymers and electron-deficient materials, such as poly(benzothiadiazole), ${ }^{20,23}$ poly(benzobisthiazole), ${ }^{24}$ poly(quinoline), ${ }^{25,26}$ cyano-substituted poly ( $p$-phenylenevinylene $),{ }^{27,28}$ 1,4-dicyanobenzene, ${ }^{29}$ a cyclometalated Ir(III) complex, ${ }^{30}$ and derivatives of cyano-substituted stilbene, ${ }^{31}$ diaryloxadiazole, ${ }^{32}$ quinoxaline, ${ }^{33}$ phenanthroline, ${ }^{34}$ and benzanthrone. ${ }^{35}$ Recent studies suggested that exciplex formation played a decisive role in electroluminescence. ${ }^{36-51}$ We envisioned that an electron-deficient coumarin could produce exciplex when embedded in electron-rich polymers, such as poly( $N$-vinylcarbazole) (PVK). Indeed, a positive driving force as large as $0.66 \mathrm{eV}$ was calculated for electron transfer from PVK to the lowest singlet excited state of coumarin (vide infra). However, to our surprise, few examples of exciplexes in coumarin compounds have been reported to date, and all the previous reports lacked spectroscopic studies. ${ }^{52-56}$

Herein, we report the execution of two prototypical strategies for turning on the fluorescence of coumarin derivatives (Scheme 1). Photoinduced charge transfer was exploited in bichromophoric dyads involving coumarin and aromatic hydrocarbons, as well as in PVK films molecularly doped with a series of coumarins, to obtain strong fluorescence emission. A series of coumarin compounds with aryl rings of increasing $\pi$ conjugation lengths were prepared (Fig. 1), and their ICT and exciplex fluorescence behaviors were systematically investigated. A photoluminescence quantum yield as high as 0.80 was obtained using the ICT approach. The exciplex strategy enabled strong and color-tuned fluorescence emission without synthetically modifying the coumarins. Mechanistic studies, including femtosecond laser

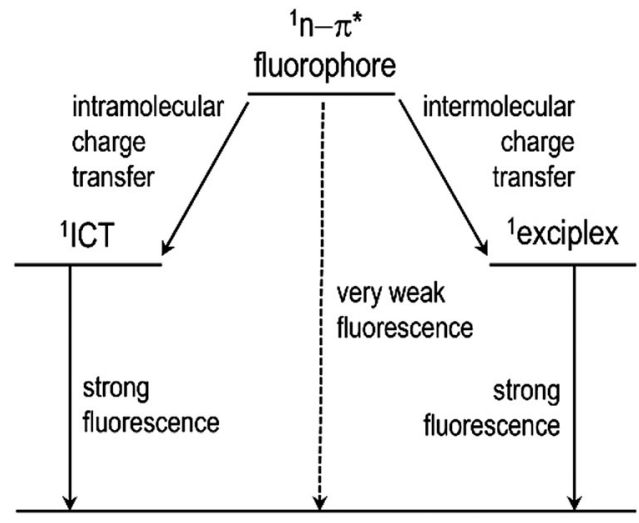

Scheme 1 Two molecular strategies for achieving strong fluorescence emission from non-fluorescent $n-\pi^{\star}$ fluorophores.

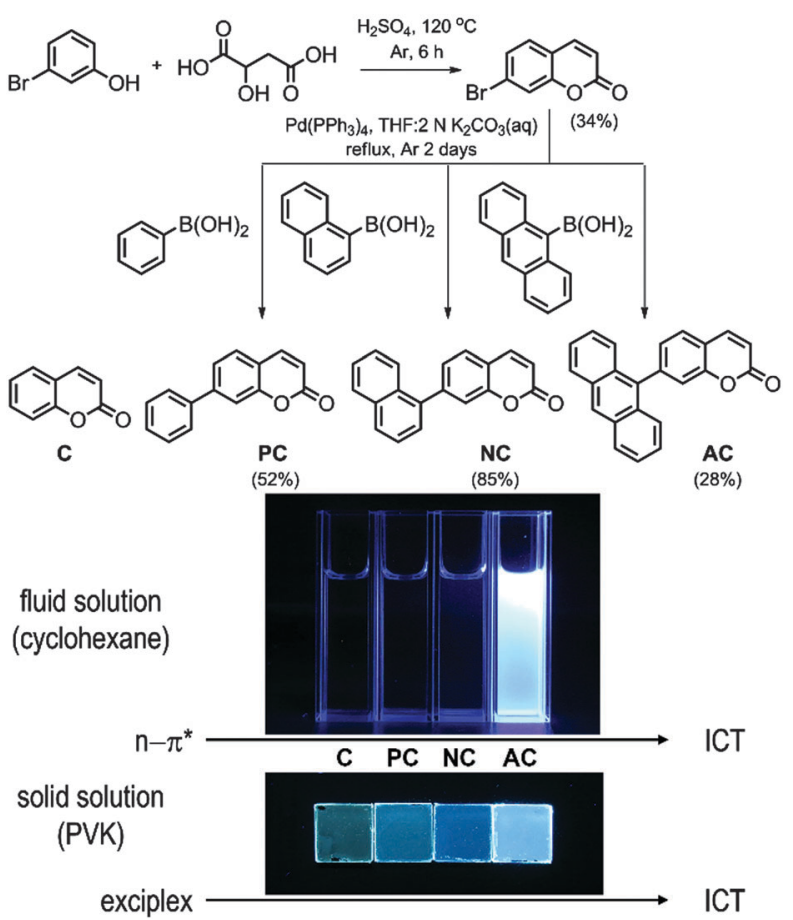

Fig. 1 Syntheses and fluorescence emission properties of the coumarin compounds.

flash photolysis experiments and quantum chemical calculations based on time-dependent density functional theory, were conducted to characterize the structure-property relationships that governed the intramolecular and intermolecular charge-transfer fluorescence. Our studies provide valuable insights into the future development of electrofluorescent materials.

\section{Results and discussion}

\section{Molecular design and synthesis}

Fig. 1 depicts the chemical structures of the coumarin molecules examined in this study. A series of coumarin compounds were designed to incorporate aryl rings with increasing $\pi$-conjugation lengths. Phenyl (PC), 1-naphthyl (NC), and 9-anthryl (AC) moieties 
were introduced at the 7 position of 1-benzopyran-2-one (C). Structural control was used to precisely tailor the electrochemical potentials of the resulting bichromophoric coumarins. Specifically, variations in the aryl groups decreased the ground-state oxidation potential $\left(E_{\mathrm{Ox}}\right)$ in the following order: $\mathrm{C}>\mathrm{PC}>\mathrm{NC}>\mathrm{AC}$, without significantly altering the ground-state reduction potential $\left(E_{\mathrm{red}}\right)$ of the coumarin derivatives. As a consequence, the ICT transition state energy, which was primarily estimated based on $E_{\mathrm{ox}}-E_{\text {red }}$, decreased from PC to AC. This energetic shift eventually situated the ICT transition state below the non-fluorescent $n-\pi^{*}$ transition state, thereby activating a fluorescence channel.

Synthetic control over the excited states was designed based on quantum chemical calculations using time-dependent density functional theory (TD-DFT, CAM-B3LYP/6-311+G(d,p)//TD-CAMB3LYP/6-311+G(d,p):CPCM(THF)). Twenty singlet and triplet states were modeled, and their electronic energies are depicted in Fig. 2. The lowest singlet states $\left(S_{1}\right)$ were predicted to predominantly possess $\pi-\pi^{*}$ character, except for AC, due to the use of the conductor-like polarizable continuum model (CPCM) parameterized for polar THF. The orthogonal disposition of the aryl ring and the coumarin plane disrupted conjugation across the entire molecule and localized the $\pi-\pi^{*}$ transition within the coumarin moiety (ESI, $\uparrow$ Fig. S1). Interestingly, increased $\pi$ conjugation in the aryl ring increased the singlet $n-\pi^{*}$ transition energies, likely due to stabilization of the non-bonding orbital on the carbonyl group. In contrast, the ICT transition energies decreased with the conjugation length. This trend persisted across the coumarin series and eventually the lowest singlet state in AC was predominantly ICT in nature. A summary of the TD-DFT calculation results for $\mathrm{C}, \mathrm{PC}, \mathrm{NC}$, and $\mathrm{AC}$ is listed in the ESI, $\dagger$ Table S1.

Control over the aryl group was intimately linked to the formation of the exciplex. Because the excited-state reduction

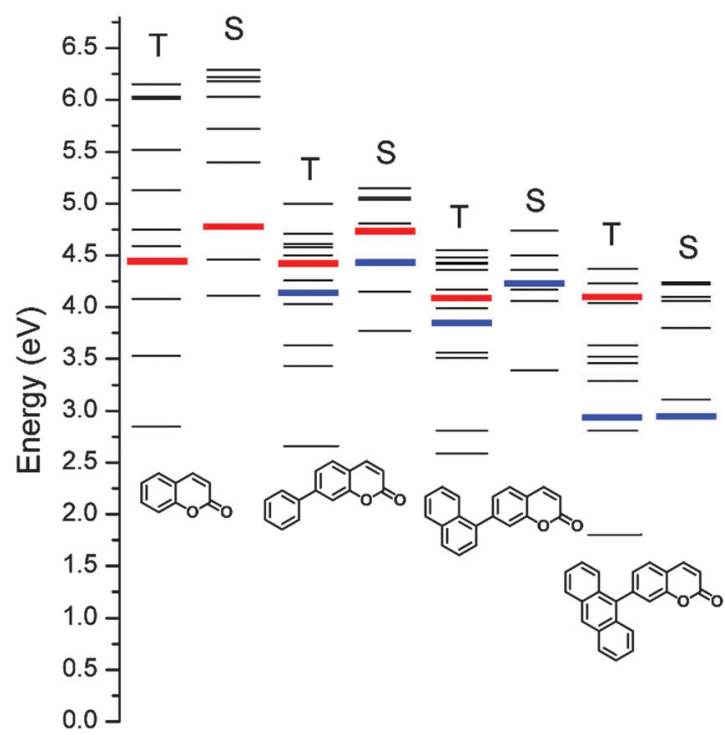

Fig. 2 Schematic representation of the calculated (CAM-B3LYP/6-311+ $\mathrm{G}(\mathrm{d}, \mathrm{p}) / / \mathrm{TD}-\mathrm{CAM}-\mathrm{B} 3 \mathrm{LYP} / 6-311+\mathrm{G}(\mathrm{d}, \mathrm{p}): \mathrm{CPCM}(\mathrm{THF})$ ) energies of the singlet $(\mathrm{S})$ and triplet $(\mathrm{T})$ excited states of the coumarin compounds. Red and blue bars indicate $n-\pi^{*}$ and ICT transition states, respectively. potential $\left(E_{\text {red }}{ }^{*}\right)$ was estimated as $E_{\text {red }}$ - band gap energy, the evolution of the aryl groups from phenyl (PC) to 9-anthryl (AC) led to a cathodic shift in $E_{\text {red }}{ }^{*}$. The free energy change for electron transfer from PVK to the excited-state coumarin compounds $\left(\Delta G_{\mathrm{eT}}\right)$ was calculated using $\Delta G_{\mathrm{eT}}=-e \cdot\left[E_{\mathrm{ox}}(\mathrm{PVK})-E_{\mathrm{red}}{ }^{*}(\right.$ coumarin $\left.)\right]$. Therefore, AC, which was characterized by the smallest $E_{\text {red }}{ }^{*}$, was expected to be least predisposed to exciplex formation, whereas $\mathrm{C}$, characterized by the largest bandgap energy (i.e., the largest $E_{\mathrm{red}}{ }^{*}$ ), favored exciplex formation.

The molecules were synthesized through a two-step procedure, which included a Pechmann condensation of $m$-bromophenol and malic acid, followed by Pd(0)-catalyzed Suzuki-Miyaura coupling using commercially available aryl boronic acid. The purified compounds were characterized by multi-nuclear NMR spectroscopy, high-resolution mass spectrometry, and elemental analysis. The characterization data were fully consistent with the proposed structures. The synthetic details and structural identification results are summarized in Experimental details.

\section{Fluorescence turn-on by intramolecular charge transfer}

With the exception of AC, the coumarin derivatives were minimally fluorescent in cyclohexane solutions at $298 \mathrm{~K}$. This observation was consistent with the calculated predictions and previous studies, which suggested that a non-radiative $n-\pi^{*}$ transition provided the dominant channel for excited-state relaxation in non-polar solvents., ${ }^{3,4}$ Indeed, the photoluminescence quantum yield (PLQY, 9,10-diphenylanthracene standard) remained as low as 0.005 for $C$. The PLQY value increased in proportion to the conjugation length of the aryl ring (Table 1). An identical trend was found in the photoluminescence lifetimes $\left(\tau_{\mathrm{obs}}\right)$ recorded at the photoluminescence peak wavelengths after picosecond pulsed photoexcitation at $377 \mathrm{~nm}$ (Table 1). $\tau_{\text {obs }}$ increased from $0.098 \mathrm{~ns}$ for $\mathrm{C}$ to $2.8 \mathrm{~ns}$ for AC. The increase was ascribed to the diminished influence of the non-emissive $n-\pi^{*}$ transition, as predicted by the TD-DFT calculations. The non-radiative rates $\left(k_{\mathrm{nr}}, k_{\mathrm{nr}}=(1-\mathrm{PLQY}) / \tau_{\mathrm{obs}}\right)$ decreased as the number of fused phenyl rings in the aryl groups increased: $\mathrm{C}, 1.0 \times 10^{10} \mathrm{~s}^{-1}$; PC, $8.2 \times 10^{9} \mathrm{~s}^{-1}$; NC, $2.6 \times 10^{9} \mathrm{~s}^{-1}$; and AC, $7.1 \times 10^{7} \mathrm{~s}^{-1}$.

The fluorescence properties of AC differed markedly from those of the other coumarin compounds. The photoluminescence emission spectrum exhibited a large $2300 \mathrm{~cm}^{-1}$ bathochromic shift relative to the spectra of the other coumarin compounds (Fig. 3). The spectral profile of AC was broad, unlike the vibronically resolved fluorescence spectrum of 9,10-diphenylanthracene. These properties suggested that an ICT transition was responsible for the observed fluorescence of AC. Strong solvatochromism, as demonstrated by the Lippert-Mataga plot, corroborated this hypothesis (ESI, $\dagger$ Fig. S2). It should be noted, however, that the extent of the solvatochromic shift was not as large as the shifts observed for conventional coumarin molecules bearing strong electron donors. ${ }^{2}$ Cyclic and differential pulse voltammetry measurements revealed a cathodic shift in the oxidation potential of AC ( $E_{\mathrm{Ox}}=1.24 \mathrm{~V} v \mathrm{~s}$. SCE $)$ relative to the $E_{\mathrm{Ox}}$ values (1.60-2.27 V vs. SCE) of the other coumarin compounds (Table 1; see the ESI, $\uparrow$ Fig. S3 for the cyclic and differential pulse voltammograms), further supporting the presence of ICT fluorescence. The ICT fluorescence was very 
Table 1 Photophysical and electrochemical data obtained from the coumarin compounds in the fluid and solid solution states

\begin{tabular}{|c|c|c|c|c|c|c|c|c|c|c|}
\hline & \multicolumn{7}{|l|}{ Fluid solution } & \multicolumn{3}{|c|}{ Solid solution $^{a}$} \\
\hline & $\begin{array}{l}\lambda_{\mathrm{abs}}{ }^{b} \\
\left(\mathrm{~nm} ; \varepsilon, 10^{4} \mathrm{M}^{-1} \mathrm{~cm}^{-1}\right)\end{array}$ & $\Delta E_{\mathrm{T}}(\mathrm{eV})$ & $\begin{array}{l}E_{\mathrm{Ox}}{ }^{e} \\
(\mathrm{~V} v s . \mathrm{SCE})\end{array}$ & $\begin{array}{l}E_{\text {red }}^{e} \\
\text { (V vs. SCE) }\end{array}$ & $\lambda_{\mathrm{ems}}^{b}(\mathrm{~nm})$ & $\mathrm{PLQY}^{b, f}$ & $\tau_{\mathrm{obs}}{ }^{g}(\mathrm{~ns})$ & $\lambda_{\text {ems }}(\mathrm{nm})$ & PLQY $^{h}$ & $\tau_{\text {avg }}{ }^{g}(\mathrm{~ns})$ \\
\hline $\mathrm{C}$ & $311(0.53)$ & $2.73^{c}$ & 2.27 & -1.75 & 388 & 0.005 & 0.098 & 458 & $0.02 \pm 0.002$ & 23 \\
\hline PC & $327(1.57)$ & $2.55^{d}$ & 1.86 & -1.66 & 396 & 0.012 & 0.12 & 469 & $0.05 \pm 0.002$ & 24 \\
\hline $\mathrm{NC}$ & $327(1.50)$ & $2.55^{d}$ & 1.60 & -1.68 & 402 & 0.081 & 0.36 & 468 & $0.04 \pm 0.01$ & 21 \\
\hline $\mathrm{AC}$ & $385(0.61)$ & N.A. & 1.24 & -1.67 & 444 & 0.80 & 2.8 & 457 & $0.18 \pm 0.006$ & 3.1 \\
\hline
\end{tabular}

${ }^{a} 10 \mathrm{wt} \%$ in PVK, $298 \mathrm{~K} .{ }^{b} 10 \mu \mathrm{M}$ in cyclohexane solutions, $298 \mathrm{~K} .{ }^{c} 50 \mu \mathrm{M}$ in 2-MeTHF, $78 \mathrm{~K} .{ }^{d} 50 \mu \mathrm{M}$ in iodoethane, $78 \mathrm{~K} .{ }^{e}$ Determined by cyclic and differential pulse voltammetry using $2.0 \mathrm{mM} \mathrm{CH}_{3} \mathrm{CN}$ solutions containing $0.10 \mathrm{M} \mathrm{TBAPF}_{6}$. Pt working and counter electrodes, and an $\mathrm{Ag} / \mathrm{AgNO}_{3} \mathrm{pseudo}$ reference electrode were employed. Scan rate $=0.10 \mathrm{~V} \mathrm{~s}^{-1}$ (cyclic voltammetry) and $4.0 \mathrm{mV} \mathrm{s}{ }^{-1}$ (differential pulse voltammetry). ${ }^{f}$ Photoluminescence quantum yields were determined relative to that of a 9,10-diphenylanthracene standard (toluene, PLQY $=1.00) .{ }^{57}{ }^{g}$ Photoluminescence decay traces for $50 \mu \mathrm{M}$ coumarin compounds in Ar-saturated toluene solutions or PVK films doped with $10 \mathrm{wt} \%$ coumarin compounds were monitored at the emission maximum after picosecond pulsed laser photoexcitation at $377 \mathrm{~nm}$. The photoluminescence lifetime $\left(\tau_{\text {obs }}\right)$ values were determined through nonlinear leastsquares fits to monoexponential (toluene solutions) or triexponential (PVK films) decay models. The weighted average lifetime ( $\left.\tau_{\text {avg }}\right)$ of triexponential decay traces was calculated using $\tau_{\text {avg }}=\left(\sum a_{i} \cdot \tau_{i}^{2}\right) /\left(\sum a_{i} \cdot \tau_{i}\right)(i=1-3)$, where $a_{i}$ and $\tau_{i}$ are the pre-exponential factor and the time constant, respectively. ${ }^{h}$ Photoluminescence quantum yields determined absolutely by integrating over a sphere. The measurements were performed in triplicate.

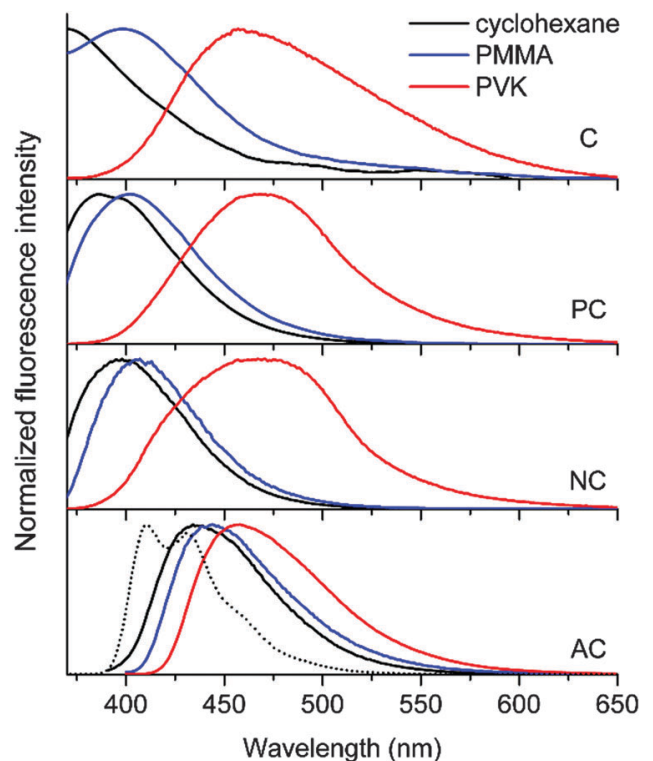

Fig. 3 Photoluminescence spectra of the coumarin compounds in fluid (10 $\mu \mathrm{M}$ in cyclohexane (black)) or solid (10 wt\% in PMMA (blue) and PVK (red)) solutions. The fluorescence spectrum of 9,10-diphenylanthracene is shown for comparison (dotted black curve). The spectra obtained in cyclohexane were truncated due to a significant overlap with the excitation beam $(375 \mathrm{~nm})$.

bright, with a PLQY as high as 0.80. This unusually high PLQY value can be ascribed to effective suppression of non-radiative transition. Indeed, the $k_{\mathrm{nr}}$ value $\left(7.1 \times 10^{7} \mathrm{~s}^{-1}\right)$ was two orders of magnitude smaller than the values $\left(10^{9}-10^{10} \mathrm{~s}^{-1}\right)$ obtained for the other coumarins. It is likely that the non-radiative control dominated over weak radiative transition of the ICT fluorescence. Taken together, these results demonstrated that the incorporation of anthracene boosted the fluorescence intensity by activating an ICT transition.

\section{Fluorescence turn-on by exciplex formation}

The non-fluorescent coumarin compounds, C, PC, and NC, became emissive when they were doped into PVK at $10 \mathrm{wt} \%$ (Fig. 1).
As shown in Fig. 3 , the fluorescence peak wavelengths $\left(\lambda_{\mathrm{ems}}\right)$ exhibited bathochromic shifts of $3500-3900 \mathrm{~cm}^{-1}$ relative to the solution spectra. The shifts did not result from planarization of the $\pi$ frameworks in the solid state because much smaller bathochromic shifts of $300-700 \mathrm{~cm}^{-1}$ were observed in poly(methyl methacrylate) (PMMA) films doped with C, PC, or NC at identical doping concentrations (10 wt\%). The PLQY values determined absolutely by integrating over a sphere were $0.02,0.05$, and 0.04 for $\mathrm{C}, \mathrm{PC}$, and $\mathrm{NC}$, respectively. These values were one order of magnitude better than the PLQY values obtained in cyclohexane solutions. By contrast, the PLQY values of the PMMA films containing $10 \mathrm{wt} \%$ coumarin compounds were relatively low: C, 0; PC, 0.019; and NC, 0.027, suggesting that rigidification did not significantly contribute to the fluorescence observed in the PVK films. ${ }^{58}$

The $\lambda_{\text {ems }}$ and PLQY values obtained from the PVK films were compared with the values obtained from the cyclohexane solutions and from the PMMA films, suggesting that the fluorescence emission did not originate from an excitonic state (a $\pi-\pi^{*}$ transition state or an ICT transition state) in the coumarin compounds. The photoluminescence peak wavelengths varied linearly with the difference between $E_{\mathrm{ox}}(\mathrm{PVK})(1.18 \mathrm{~V} v s \text {. SCE })^{59}$ and the ground-state reduction potential $\left(E_{\text {red }}: \mathrm{C},-1.75 \mathrm{~V} ; \mathrm{PC}\right.$, $-1.66 \mathrm{~V} ; \mathrm{NC},-1.68 \mathrm{~V}$ vs. SCE) of the coumarin derivatives (Table 1). The UV-vis absorption spectrum of C in the 2-MeTHF solution $(10 \mu \mathrm{M})$ was compared with the spectra obtained from the PMMA (10 wt\%) and PVK (10 wt\%) solid solutions to reveal the absence of ground-state charge-transfer interactions between the coumarin derivatives and PVK (Fig. 4).

To gain additional information about the nature of the fluorescence emission, photoluminescence decays were monitored for the coumarin-doped (10 wt $\%$ ) PVK films at the emission peak wavelengths after picosecond pulsed laser photoexcitation at $377 \mathrm{~nm}$. The decay trace of a PVK film containing NC exhibited a multi-exponential decay behavior (Fig. 5). This multiphasic decay markedly differed from those of NC in a fluid solution (50 $\mu \mathrm{M}$ in Ar-saturated toluene) and a PMMA film (10 wt $\%)$, which adhered to a monoexponential decay model with $\tau_{\text {obs }}$ values in the subnanosecond ranges. A weighted average photoluminescence 


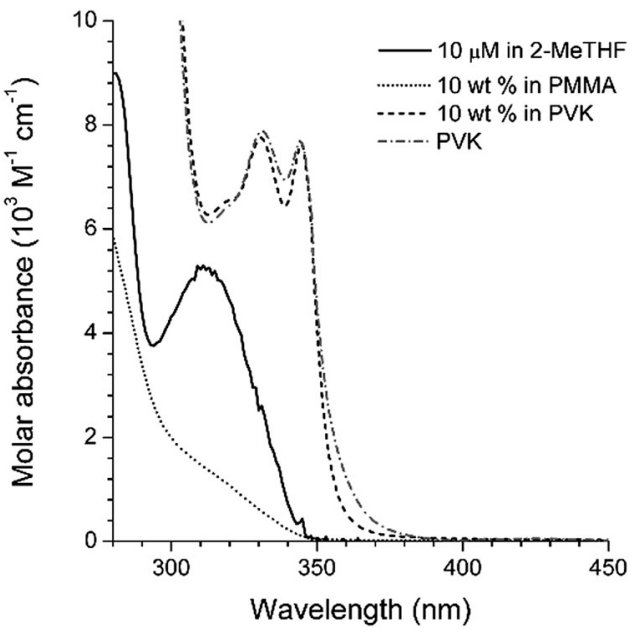

Fig. 4 UV-vis absorption spectra of $\mathrm{C}$ measured in fluid $(10 \mu \mathrm{M}$ in 2-MeTHF (solid black line)) or solid (10 wt\% in PMMA (dotted grey line) or PVK (dashed black line)) solutions. The absorption spectrum of PVK (dashed grey line) is included for comparison. See the ESI, $\dagger$ Fig. S4 for the spectra of the other compounds.

lifetime of the PVK film of NC was 21 ns, being two orders of magnitude longer than those of the solution ( $0.36 \mathrm{~ns}$; Table 1$)$. The transient photophysical properties were consistent with the previous observations of exciplex fluorescence. ${ }^{23,31,60,61}$ The exciplex fluorescence featured several unique properties: (1) prolonged lifetimes of the emissive state, and (2) emission color which was determined by the relative position of electrochemical potentials of individual components (i.e., coumarin and PVK). Inspection of Table 1 reveals interesting trends; the $\tau_{\text {obs }}$ values of the fluid solutions increased with the $\pi$ conjugation lengths of the aryl ring (C, 0.098 ns; PC, 0.12 ns; NC, 0.36 ns; and AC, 2.8 ns).

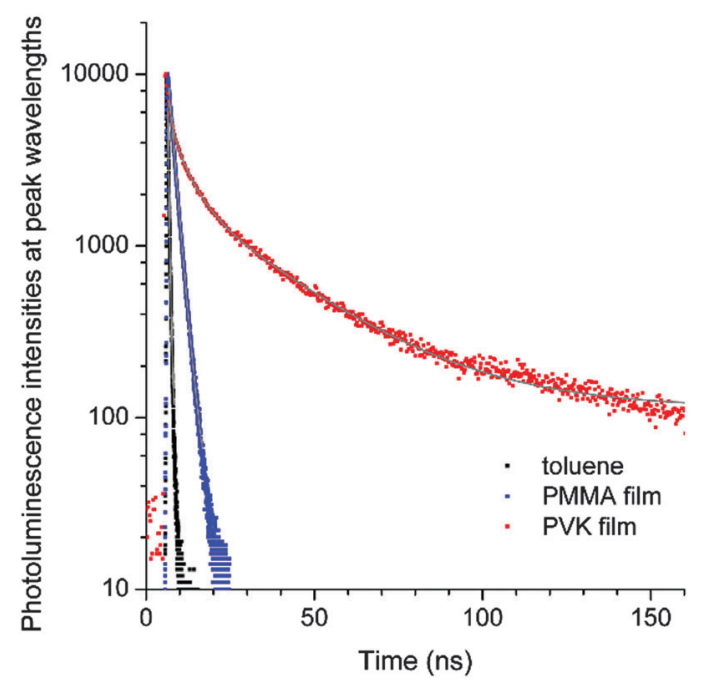

Fig. 5 Photoluminescence decay traces of NC after picosecond pulsed laser excitation at $377 \mathrm{~nm}$ (pulse duration = $8 \mathrm{ps}$ ): black, $50 \mu \mathrm{M}$ in an Ar-saturated toluene solution; blue, 10 wt\% in a PMMA film; and red, 10 wt\% in a PVK film. The grey curves are non-linear least squares fits to monoexponential (black and blue) and triexponential (red) decay models. Refer to the ESI, $\dagger$ Fig. S5 for the decay traces of C, PC and AC, and Table 1 for the fit results.
This observation could be explained on the basis of the decreasing contribution of $n-\pi *$ transition for the coumarin compounds with $\pi$-extended rings, as explained earlier. The influence of the fluorescence quenching $\mathrm{n}-\pi^{*}$ transition was suppressed in PVK, because emissive exciplex species provided the lowest energy path for excited-state relaxation. In fact, such non-radiative control yielded the observed trend in the ratio of PLQY(PVK)/PLQY(cyclohexane). For instance, $C$ with the strong quenching contribution by $n-\pi^{*}$ transition in fluid solutions showed the largest value for the ratio (12) of PLQY(PVK)/PLQY(cyclohexane). The ratio decreased with the conjugation length of the aryl rings: $\mathrm{PC}, 4.2$; NC, 0.49. In the case of $\mathrm{AC}$, the fluorescence properties were not affected by PVK. The emission peak wavelength of the PVK film (10 wt\% doping ratio, $457 \mathrm{~nm})$ did not exhibit a significant bathochromic shift from that (444 nm) of the cyclohexane solution. Similarly, the $\tau_{\text {obs }}$ value (3.1 ns) was nearly identical to that obtained in the cyclohexane solution (2.8 ns). Time-resolved photoluminescence spectra of PVK films doped with either $10 \mathrm{wt} \%$ PC or $10 \mathrm{wt} \%$ AC revealed contrasting behaviors (Fig. 6). The retention of the fluorescence properties may be indicative of the absence of the exciplex channel in AC.

Fluorescence utility of the exciplex of the coumarin compounds was demonstrated by emission color tuning. PVK films containing $10 \mathrm{wt} \% \mathrm{C}$ were additionally doped with several electron donors (30 wt\%) having the $E_{\mathrm{Ox}}$ values smaller than that of PVK: 1,2-dimethylindole (DMI), $1.06 \mathrm{~V} ; N, N$-dimethylaniline (DMA), $0.77 \mathrm{~V}$; and $N, N$-dimethyl-p-toluidine (DMT), $0.72 \mathrm{~V}$ (all potentials are vs. SCE). ${ }^{62}$ As shown in Fig. 7a, the exciplex fluorescence emission of the ternary mixtures shifted bathochromically with decreasing $E_{\text {ox }}$ of the electron donors. Indeed, the fluorescence peak energies exhibited linear proportionality to the values of $E_{\text {ox }}$ (donor) $-E_{\text {red }}(\mathrm{C})$ (Fig. 7b). The photoluminescence decay traces monitored at the emission peak wavelengths followed a triexponential decay model, as seen for the binary mixture of $\mathrm{C}$ and PVK. The weighted average values of the photoluminescence decay were as long as $8.3 \mathrm{~ns}, 13.8 \mathrm{~ns}$, and $9.2 \mathrm{~ns}$ for 1,2-dimethylindole, $N, N$-dimethylaniline, and $N, N$-dimethyl- $p$ toluidine, respectively (ESI, $\dagger$ Fig. S7). These results unambiguously demonstrated that the exciplex is the origin of fluorescence emission, and provided a versatile strategy to tailor fluorescence emission.

\section{Photophysical monitoring of the excited-state processes}

Having demonstrated the ICT and exciplex emission, we sought to investigate the photophysical processes. Scheme 2 depicts the plausible mechanisms for the photophysical processes in AC (i.e., ICT fluorescence) and PVK films containing PC (i.e., exciplex fluorescence). In both cases, the charge transfer provides fluorescence channels that can harvest the excited-state energy of the $n-\pi^{*}$ transition state. It should be noted that, without the new channels mediated by charge transfer, the $n-\pi^{*}$ transition state relaxes to the ground state non-radiatively.

The steady-state and transient photoluminescence results revealed that the ICT transition state is responsible for the fluorescence emission of AC. To directly probe the ICT process, femtosecond laser flash photolysis experiments were performed. 
(a)

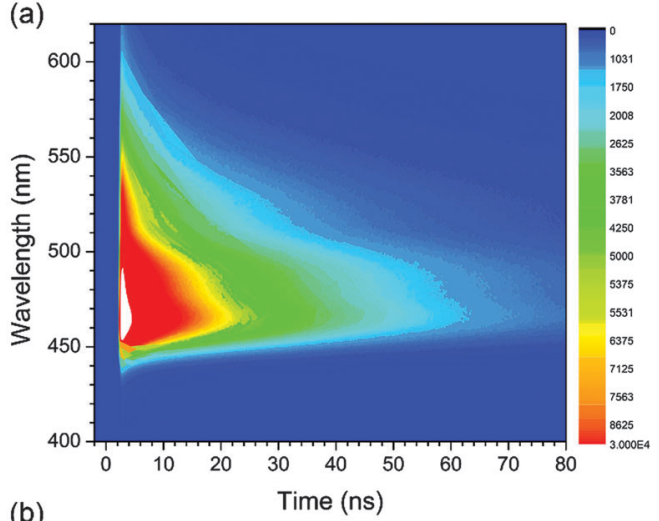

(b)

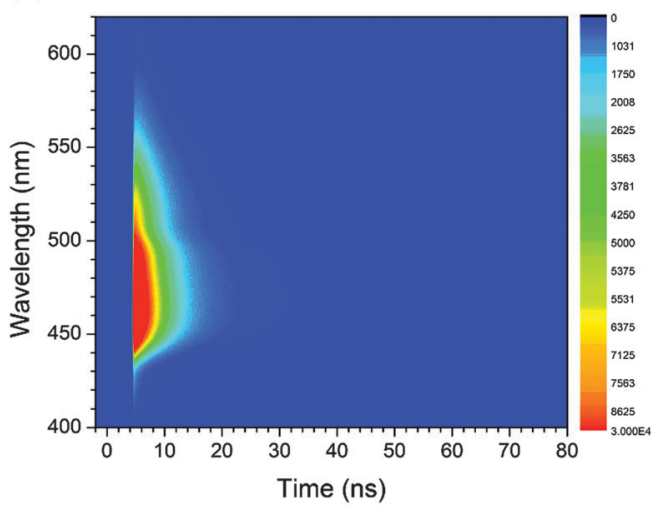

Fig. 6 Time-resolved photoluminescence spectra of PVK films doped with 10 wt $\%$ PC (a) and 10 wt\% AC (b) after picosecond pulsed laser excitation at $377 \mathrm{~nm}$.

The transient absorption spectra of toluene solutions of AC (O.D. $=0.2$ at $350 \mathrm{~nm}$ ) were acquired after femtosecond pulsed laser photoexcitation at $350 \mathrm{~nm}$. As shown in Fig. 8a, a strong absorption band at $620 \mathrm{~nm}$ appeared at a rise time of $0.78 \mathrm{ps}$, (a)

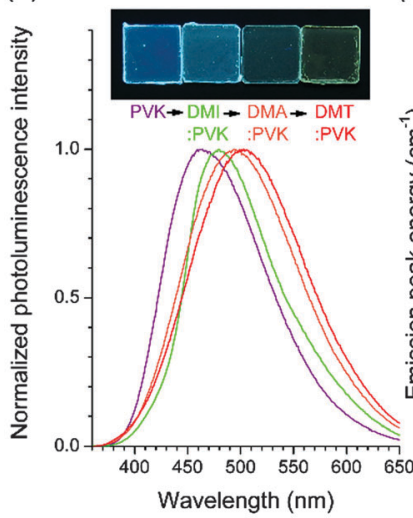

(b)

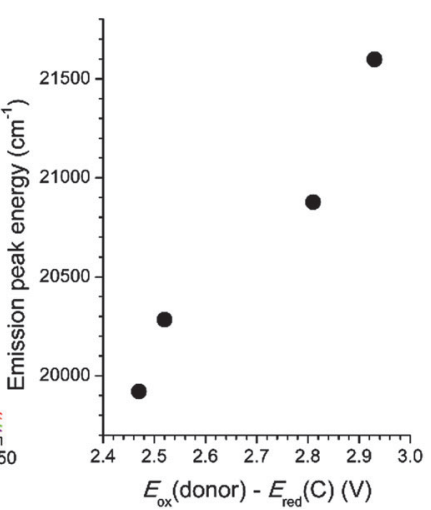

Fig. 7 (a) Photoluminescence spectra of PVK films doped with $10 \mathrm{wt} \% \mathrm{C}$ and a 30 wt\% electron donor. Electron donors: DMI, 1,2-dimethylindole; DMA, $N, N$-dimethylaniline; and DMT, N,N-dimethyl- $p$-toluidine. The inset photograph shows the fluorescence emission of the PVK films of $10 \mathrm{wt} \% \mathrm{C}$ in the absence (far left) and presence of DMI, DMA, and DMT (from the second left). (b) Plot of the fluorescence peak wavelength energies and the difference between the ground-state oxidation potentials of the electron donors $\left(E_{\text {ox }}(\right.$ donor $\left.)\right)$ and the ground-state reduction potentials of $C\left(E_{\text {red }}(C)\right)$.

and decayed with a time constant of $1.2 \mathrm{~ns}$. The $620 \mathrm{~nm}$ band was due to the radical cation of the coumarin moiety, ${ }^{63}$ while the anthracene radical cation was shown at $720 \mathrm{~nm}$ as a shoulder band. ${ }^{63-67}$ The rise ( $0.78 \mathrm{ps}$ ) and decay (1.2 ns) times may correspond to the time required for relaxation to the lowest ICT transition and ground states, respectively. The latter time constant was indistinguishable from the photoluminescence lifetime of AC recorded in toluene (2.8 ns), further supporting this notion. By contrast, the transient absorption spectra of the other coumarin compounds differed from that of AC, and included a transient absorption band at $550 \mathrm{~nm}$. The $550 \mathrm{~nm}$ absorption bands were long-lived and did not decay appreciably until 3000 ps (ESI, $\dagger$ Fig. S8).
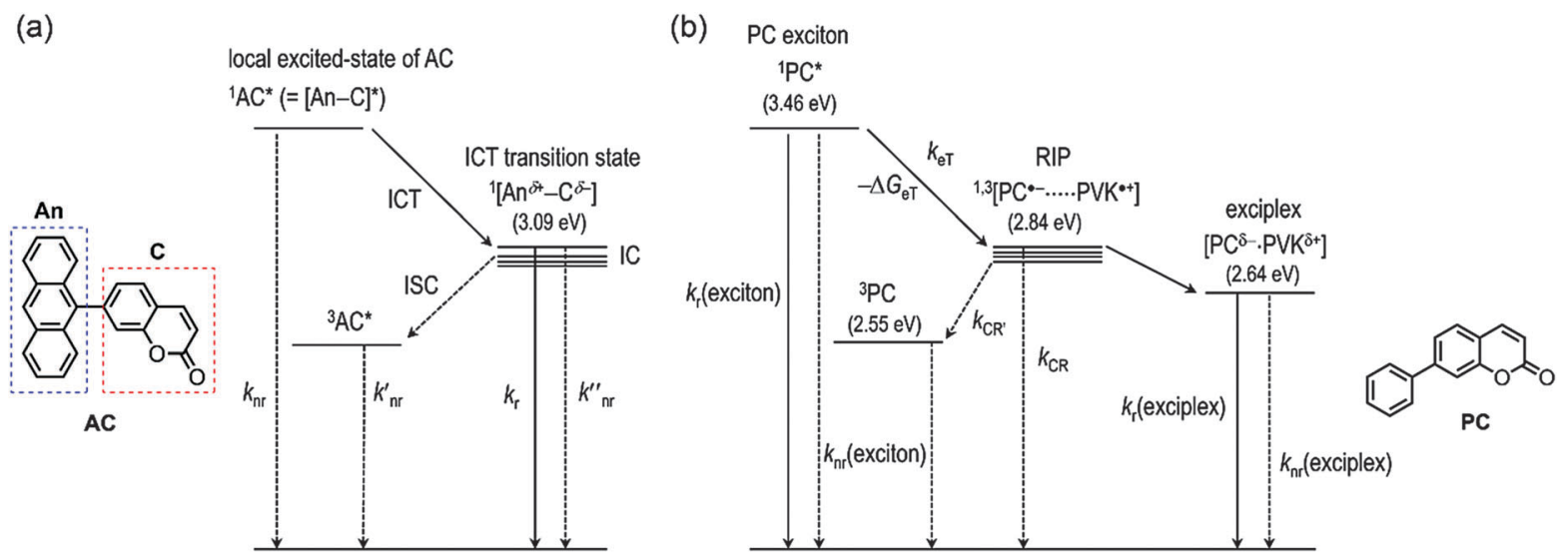

Scheme 2 Plausible mechanisms for (a) the ICT fluorescence of AC and (b) generation and relaxation of the exciplex in PVK films doped with PC upon photoexcitation: ISC, intersystem crossing; IC, internal conversion; RIP, radical ion pair; $k_{n \text { r }}$ the rate constant for non-radiative decay of the singlet local excited state of $\mathrm{AC} ; k_{n r}^{\prime}$, the rate constant for non-radiative decay of the triplet local excited state of $\mathrm{AC} ; k_{\mathrm{r}}$, the rate constant for radiative decay of the ICT transition state of $\mathrm{AC} ; k^{\prime \prime}{ }_{n r}$, the rate constant for non-radiative decay of the ICT transition state of $\mathrm{AC} ; k_{\mathrm{r}}$ (exciton), the rate constant for radiative decay of $\mathrm{PC} ; k_{\mathrm{nr}}$ (exciton), the rate constant for non-radiative decay of $\mathrm{PC} ; k_{\mathrm{e}}$, the rate constant for photoinduced electron transfer from PVK to PC; $k_{\mathrm{CR}}{ }^{\prime}$, the rate constant for charge recombination to the triplet state of $\mathrm{PC} ; k_{C R}$, the rate constant for charge recombination to the ground state of $\mathrm{PC} ; k_{\mathrm{r}}(\mathrm{exciplex)}$, the rate constant for radiative decay of the exciplex; and $k_{n r}$ (exciplex), the rate constant for non-radiative decay of the exciplex. 
(a)

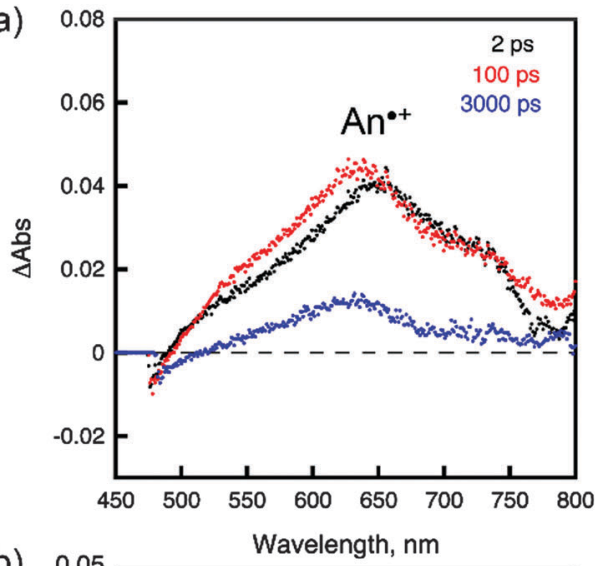

(b)

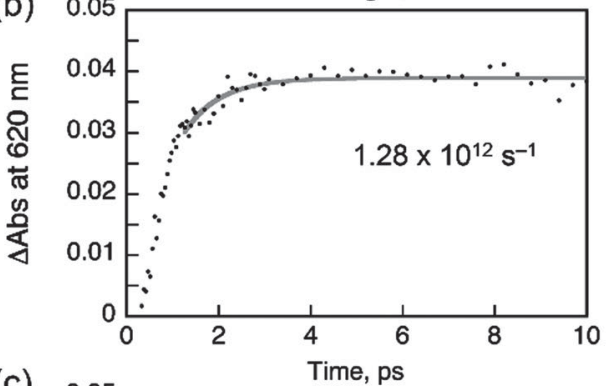

(c)

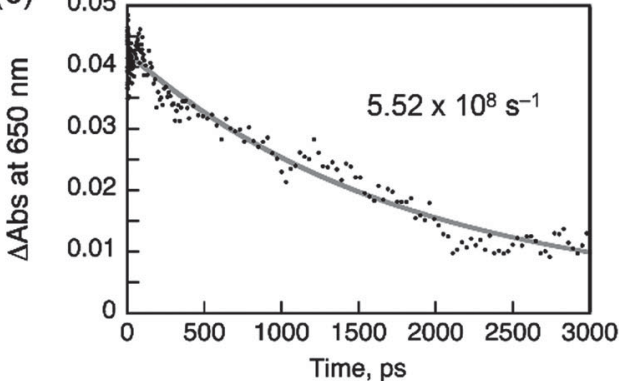

Fig. 8 Femtosecond laser flash photolysis of a toluene solution of $\mathrm{AC}$ (O.D. $=0.2$ at $350 \mathrm{~nm}, 2 \mathrm{~mm}$ pathlength). (a) Transient absorption spectra recorded at 2, 100 and $3000 \mathrm{ps}$ after photoexcitation at $350 \mathrm{~nm}$. (b) Rising traces of the transient absorption at $620 \mathrm{~nm}$ and the nonlinear least squares fit. (c) Decay traces of the transient absorption at $650 \mathrm{~nm}$ and the nonlinear least squares fit. See the ESI, $\dagger$ Fig. S8 for the laser flash photolysis results obtained from C, PC and NC.

Photoexcitation under UV irradiation $(365 \mathrm{~nm})$ produced excited states in both $\mathrm{PC}\left(\mathrm{PC}^{*}\right)$ and $\mathrm{PVK}\left(\mathrm{PVK}^{*}\right)$; however, electron transfer was only allowed from the ground state of $\mathrm{PVK}$ to $\mathrm{PC}^{*}$ due to a positive driving force (i.e., $-\Delta G_{\mathrm{eT}}$ ) of $0.62 \mathrm{eV}$, which was determined by the difference between the $E_{\mathrm{red}}{ }^{*}$ of PC and $E_{\mathrm{ox}}$ of PVK. Other coumarin derivatives also displayed a positive driving force for the photoinduced reductive electron transfer from PVK: $0.66 \mathrm{eV}(\mathrm{C}), 0.57 \mathrm{eV}(\mathrm{NC})$, and $0.24 \mathrm{eV}(\mathrm{AC})$. By contrast, electron transfer from the coumarin derivative to the excited state of PVK $\left(\mathrm{PVK}^{*}\right)$ was forbidden due to the negative driving force $\left(-\Delta G_{\mathrm{eT}}=-0.10 \mathrm{eV}\right.$ to $\left.-0.19 \mathrm{eV}\right)$. The photoinduced electron transfer produced a radical ion pair $\left(\left[\mathrm{PC}^{-}{ }^{-} \mathrm{PVK}^{{ }^{+}}\right]\right)$ consisting of a one-electron reduced $\mathrm{PC}$ species $\left(\mathrm{PC}^{--}\right)$and a one-electron oxidized $\mathrm{PVK}$ species $\left(\mathrm{PVK}^{{ }^{+}}\right)$. We attempted to determine the rate constant for intermolecular electron transfer using transient photoluminescence techniques by adding

$\mathrm{N}$-ethylcarbazole into the coumarin solutions; however, the experiments were hampered by a significant overlap between the fluorescence spectra of $N$-ethylcarbazole and the coumarin derivatives. Femtosecond laser flash photolysis revealed an ultrafast increase in the $\mathrm{PVK}^{\circ}$ signal within the temporal resolution of the instrument (vide infra), indicating the presence of forward electron transfer. Once the $\left[\mathrm{PC}^{\bullet-} \mathrm{PVK}^{\bullet+}\right]$ has been generated, it underwent charge recombination to produce ground states (CR in Scheme 2b) in PC and PVK or a triplet excited state $\left(\mathrm{CR}^{\prime}\right.$ in Scheme $\left.2 \mathrm{~b}\right)$ in PC. An alternative pathway may involve the formation of a fluorescent exciplex. Although the limited spectral resolution impeded discrimination among these three processes, we detected the transient absorption band of $\mathrm{PVK}^{\bullet+}$ at $770 \mathrm{~nm}$ in PVK films composed of $10 \mathrm{wt} \%$ PC after femtosecond pulsed laser photoexcitation at $350 \mathrm{~nm}$ (Fig. 9a). A high-energy absorption band at $490 \mathrm{~nm}$ corresponded to a triplet transition $\left(\mathrm{T}_{1} \rightarrow \mathrm{T}_{n}\right)$ in PC. ${ }^{7}$ These assignments were consistent with those reported previously. ${ }^{62,68-70}$ The observation of the $\mathrm{PVK}^{\circ+}$ species enabled us to follow the decay of $\left[\mathrm{PC}^{\bullet}{ }^{-} \mathrm{PVK}^{\bullet+}\right.$. As shown in Fig. 9b, the transient absorption of $\mathrm{PVK}^{\bullet+}$ underwent biexponential decay with a weighted average rate $\left(k_{\text {decay }}(\mathrm{RIP})\right)$ of $2.6 \times 10^{9} \mathrm{~s}^{-1}$. The $k_{\text {decay }}(\mathrm{RIP})$ corresponded to a sum of rate constants for charge recombination to the

\section{(a)}

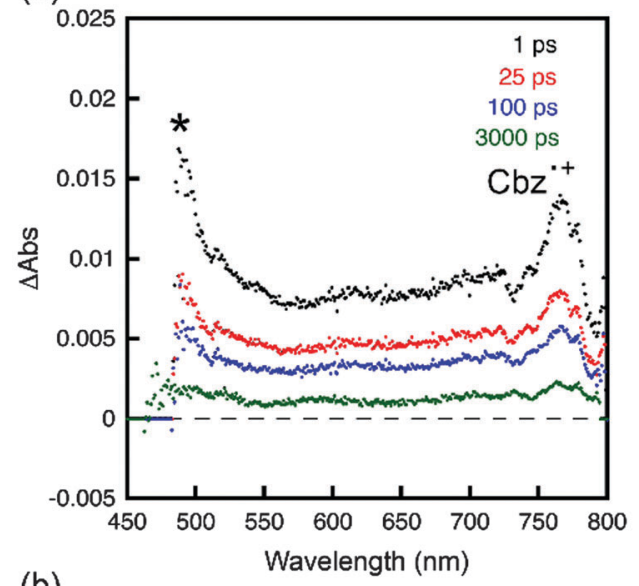

(b)

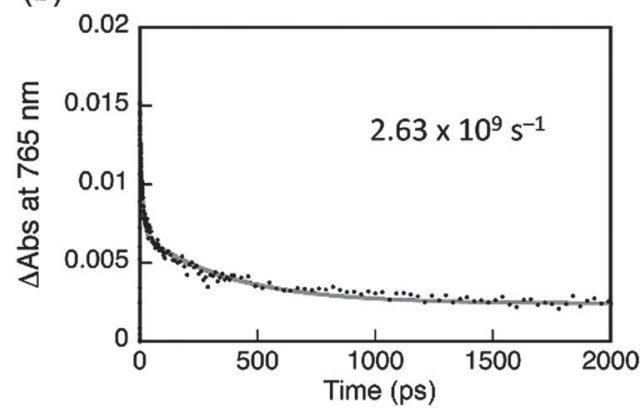

Fig. 9 Femtosecond laser flash photolysis of a PVK film doped with 10 wt\% PC. (a) Transient absorption spectra recorded at 1, 25, 100, and $1000 \mathrm{ps}$ after photoexcitation at $350 \mathrm{~nm}$. The absorption band indicated by an asterisk $\left(^{*}\right)$ corresponds to the $T_{1} \rightarrow T_{n}$ transition in PC. (b) Decay traces of the transient absorption at $765 \mathrm{~nm}$ and a nonlinear least squares fit to a biexponential decay model. See the ESI, $\dagger$ Fig. 59 for the laser flash photolysis results obtained from $\mathrm{C}, \mathrm{NC}$, and AC. 
Table 2 Summary of the rate values characterizing the photophysical processes in the PVK films containing the coumarin compounds

\begin{tabular}{|c|c|c|c|c|c|}
\hline & \multicolumn{2}{|l|}{ Exciton $^{a}$} & \multicolumn{2}{|l|}{ Exciplex $^{b}$} & \multirow{2}{*}{$\begin{array}{l}k_{\text {decay }}(\mathrm{RIP}) \\
\left(10^{9} \mathrm{~s}^{-1}\right)\end{array}$} \\
\hline & $k_{\mathrm{r}}^{d}\left(10^{7} \mathrm{~s}^{-1}\right)$ & $k_{\mathrm{nr}}^{e}\left(10^{7} \mathrm{~s}^{-1}\right)$ & $k_{\mathrm{r}}^{f}\left(10^{7} \mathrm{~s}^{-1}\right)$ & $k_{\mathrm{nr}}{ }^{g}\left(10^{7} \mathrm{~s}^{-1}\right)$ & \\
\hline C & 0 & 14 & 0.26 & 4.1 & 9.8 \\
\hline PC & 0.23 & 12 & 0.21 & 4.0 & 2.6 \\
\hline NC & 1.4 & 38 & 0.16 & 4.6 & 3.8 \\
\hline $\mathrm{AC}$ & 24 & 35 & N.A. & N.A. & N.A. \\
\hline
\end{tabular}

${ }^{a} 10 \mathrm{wt} \%$ in PMMA films, $298 \mathrm{~K} .{ }^{b} 10 \mathrm{wt} \%$ in PVK films, $298 \mathrm{~K} .{ }^{c}$ Decay rate of the radical ion pair of PVK and coumarin compound species, determined by laser flash photolysis after femtosecond laser photoexcitation of the PVK films containing $10 \mathrm{wt} \%$ coumarin compounds at $330 \mathrm{~nm}(\mathrm{C})$ and $350 \mathrm{~nm}$ (PC, NC, and AC). ${ }^{d}$ Radiative rate constant, $k_{\mathrm{r}}=\mathrm{PLQY} / \tau_{\mathrm{obs}}: \mathrm{PLQY}=0(\mathrm{C}), 0.019 \pm 0.0008(\mathrm{PC}), 0.27 \pm 0.007(\mathrm{NC})$, and $0.41 \pm 0.002(\mathrm{AC}) ; \tau_{\mathrm{obs}}=7.4 \mathrm{~ns}(\mathrm{C}), 8.4 \mathrm{~ns}(\mathrm{PC}), 1.9 \mathrm{~ns}(\mathrm{NC})$, and $1.7 \mathrm{~ns}$ (AC). ${ }^{e}$ Non-radiative rate constant, $k_{\mathrm{nr}}=(1-\mathrm{PLQY}) / \tau_{\mathrm{obs}} \cdot{ }^{f}$ Radiative rate constant, $k_{\mathrm{r}}=\mathrm{PLQY} / \tau_{\mathrm{obs}}$ : see Table 1 for the PLQY and $\tau_{\mathrm{obs}}$ values. ${ }^{g}$ Non-radiative rate constant, $k_{\mathrm{nr}}=(1-\mathrm{PLQY}) / \tau_{\mathrm{obs}}$.

ground state $\left(k_{\mathrm{CR}}\right.$ in Scheme $\left.2 \mathrm{~b}\right)$ and the triplet state $\left(k_{\mathrm{CR}^{\prime}}\right.$ in Scheme $2 \mathrm{~b}$ ) and conversion to the exciplex. The decay rate exceeded the radiative ( $k_{\mathrm{r}}$ (exciplex), $2.1 \times 10^{6} \mathrm{~s}^{-1}$ ) and non-radiative ( $k_{\mathrm{nr}}\left(\right.$ exciplex), $4.0 \times 10^{7} \mathrm{~s}^{-1}$ ) decay rates of the exciplex of PC by three and two orders of magnitudes, respectively (Table 2), indicating that charge recombination was faster than the relaxation of the exciplex. Similarly, the $k_{\text {decay }}(\mathrm{RIP})$ values of C and NC were as large as $9.8 \times 10^{9} \mathrm{~s}^{-1}$ and $3.8 \times 10^{9} \mathrm{~s}^{-1}$, respectively (Table 2). Unlike the transient absorption spectra of C, PC, and NC compounds, the transient absorption spectrum of PVK films of AC lacked the $\mathrm{PVK}^{\bullet+}$ band (ESI, $\dagger$ Fig. S9). This observation indicated that intermolecular electron transfer between PVK and $\mathrm{AC}$ was suppressed, despite the positive driving force $(0.24 \mathrm{eV})$, most likely due to the presence of ICT transition.

It should be noted that the decay rates were proportional to the free energy change for back electron transfer within the radical ion pair to yield the ground states $\left(\Delta G_{\mathrm{BeT}}(\mathrm{G}): \mathrm{C},-2.93 \mathrm{eV} ; \mathrm{PC},-2.84 \mathrm{eV}\right.$; $\mathrm{NC},-2.86 \mathrm{eV})$. The $\Delta G_{\mathrm{BeT}}(\mathrm{G})$ values were calculated using the relationship, $\Delta G_{\mathrm{BeT}}(\mathrm{G})=-e \cdot\left[E_{\mathrm{red}}(\right.$ coumarin $\left.)-E_{\mathrm{ox}}(\mathrm{PVK})\right]$, where $e$ is the elementary charge of an electron. The free energy change for

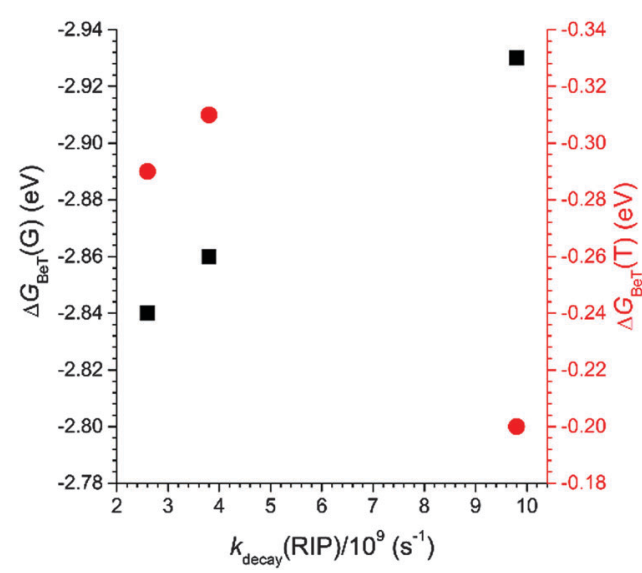

Fig. 10 Plots of the free energy change for charge recombination within the radical ion pair $\left[\mathrm{PC}^{\bullet-} \mathrm{PVK}^{\bullet+}\right.$ ] to the ground $\left(\Delta G_{\mathrm{BeT}}(\mathrm{G})\right)$ and triplet $\left(\Delta G_{\mathrm{BeT}}(\mathrm{T})\right)$ states of the coumarin compounds as a function of the rate constant for the decay of the radical ion pair $\left(k_{\text {decay }}(R I P)\right)$. charge recombination to the triplet state of coumarin $\left(\Delta G_{\mathrm{BeT}}(\mathrm{T})\right.$ : C, $-0.20 \mathrm{eV} ; \mathrm{PC},-0.29 \mathrm{eV} ; \mathrm{NC},-0.31 \mathrm{eV}$ ) was calculated from the difference between $-\Delta G_{\mathrm{BeT}}(\mathrm{G})$ and the triplet state energies $\left(\Delta E_{\mathrm{T}}\right)$ of the coumarin compounds. The $\Delta E_{\mathrm{T}}$ values were determined from the low temperature $(78 \mathrm{~K})$ phosphorescence spectra collected from solutions containing $50 \mu \mathrm{M} \mathrm{C}$ in 2-MeTHF or $50 \mu \mathrm{M}$ PC or NC in iodoethane (ESI, $\dagger$ Fig. S5). As shown in Fig. 10, the $k_{\text {decay }}(\mathrm{RIP})$ varied linearly with $\Delta G_{\mathrm{BeT}}(\mathrm{G})$ but not with $\Delta G_{\mathrm{BeT}}(\mathrm{T})$. Taken together, these results suggest that the favored relaxation process for the photo-produced radical ion pair involved non-radiative charge recombination to the ground state, which occurred in the Marcus-normal region of electron transfer.

\section{Summary and conclusions}

$\mathrm{n}-\pi^{*}$ chromophores are considered to be weak fluorophores, because they undergo fast non-radiative relaxation. The utility of $n-\pi^{*}$ fluorophores has not been appreciated, and successful applications of these compounds are scarce, with the exception of coumarin compounds bearing strong electron donors. We sought to improve the fluorescence properties of $n-\pi^{*}$ fluorophores by implementing two photophysical design strategies. These strategies promoted intra- and intermolecular charge transfer to electrondeficient $n-\pi^{*}$ fluorophores, and generated an ICT transition state and an exciplex, both of which were fluorescent. The archetype 1-benzopyran-2-one (coumarin) was chosen as a model platform. Aryl rings, including phenyl (PC), 1-naphthyl (NC), and 9-anthryl (AC), were introduced at the 7 position of coumarin. AC was found to display strong ICT fluorescence emission, whereas the fluorescence intensities of coumarin and the other derivatives were very low. The increase in fluorescence was ascribed to the reordering of the electronic states through the generation of an ICT transition state and destabilization of the $\mathrm{n}-\pi^{*}$ transition state. The weakly emissive C, PC, and NC became highly fluorescent when doped into PVK films. The fluorescence originated from the exciplex, as demonstrated by the mechanistic studies. Femtosecond laser flash photolysis experiments enabled us to directly identify the electron-transfer species generated during the exciplex de-excitation processes. The relationship between the electron-transfer rates and the driving force for electron transfer revealed that fast charge recombination provided the dominant relaxation pathway. This establishment delivered valuable insights that further improved the fluorescence properties. Recent studies have described the utility of electron-transfer species as emitting centers, ${ }^{7-103}$ whereas the molecular principles underlying high-efficiency exciplex fluorescence have yet to be fully established. We hope that the results presented here will provide useful insights into the future utilization of charge-transfer fluorescence.

\section{Experimental details}

\section{Synthetic methods}

Commercially available chemicals were used as received. All glassware, syringes, and magnetic stir bars were thoroughly dried in a convection oven. Reactions were monitored using 
thin layer chromatography (TLC) using commercial TLC plates (silica gel 60 F254, Merck Co.). Silica gel column chromatography was performed with silica gel 60 (particle size $0.063-0.200 \mathrm{~mm}$, Merck Co.). ${ }^{1} \mathrm{H}$ and ${ }^{13} \mathrm{C}$ NMR spectra were collected using Bruker, Ultrashield 300, 400, and 500 NMR spectrometers and were referenced to TMS. High-resolution mass spectra were acquired using JEOL, JMS-600W/JMS-700GC and Applied Biosystems, Tempo Nano HPLC/QSTAR Elite spectrometers. Elemental analysis was performed using a CE Instrument, EA1110 instrument.

Synthesis of 7-bromocoumarin. To a mixture of 3-bromophenol (5.00 g, $28.9 \mathrm{mmol})$ and DL-malic acid (2.60 g, $19.4 \mathrm{mmol})$ at $0{ }^{\circ} \mathrm{C}$ was added dropwise $98 \% \mathrm{H}_{2} \mathrm{SO}_{4}(6.5 \mathrm{~mL})$. The resulting solution was heated at $120{ }^{\circ} \mathrm{C}$ for $6 \mathrm{~h}$. The reaction mixture was poured into crushed ice, and the precipitated solids were collected by filtration. The filter cake was washed thoroughly with water to remove residual $\mathrm{H}_{2} \mathrm{SO}_{4}$. The solid was dissolved in $\mathrm{CH}_{2} \mathrm{Cl}_{2}$, dried over anhydrous $\mathrm{MgSO}_{4}$, and concentrated under vacuum. Silica gel column purification with $\mathrm{CH}_{2} \mathrm{Cl}_{2}: n$-hexane $=1: 1(\mathrm{v} / \mathrm{v})$ yielded a white powder in a $34 \%$ yield. ${ }^{1} \mathrm{H}$ NMR (400 $\left.\mathrm{MHz}, \mathrm{CDCl}_{3}\right) \delta: 6.44$ (d, $J=9.6 \mathrm{~Hz}, 1 \mathrm{H}), 7.337 .43(\mathrm{~m}, 2 \mathrm{H}), 7.52(\mathrm{~d}, J=2.0 \mathrm{~Hz}, 1 \mathrm{H}), 7.66$ $(\mathrm{d}, J=9.6 \mathrm{~Hz}, 1 \mathrm{H}) .{ }^{13} \mathrm{C} \mathrm{NMR}\left(75 \mathrm{MHz}, \mathrm{CDCl}_{3}\right) \delta: 117.01,117.90$, 120.29, 125.93, 128.02, 128.97, 142.92, 154.40, 160.01.

Synthesis of PC. 7-Bromocoumarin ( $0.300 \mathrm{~g}, 1.33 \mathrm{mmol})$, phenylboronic acid $(0.195 \mathrm{~g}, 1.60 \mathrm{mmol})$, and tetrakis(triphenylphosphine)palladium(0) (0.077 g, $0.07 \mathrm{mmol})$ were added into a $100 \mathrm{~mL}$ round-bottom flask. The reaction mixtures were dissolved in THF: $2 \mathrm{~N} \mathrm{~K}_{2} \mathrm{CO}_{3}$ (aq.) $(2: 1, \mathrm{v} / \mathrm{v})$ and refluxed for 2 days. The cooled reaction mixture was poured onto water, and extracted with $\mathrm{CH}_{2} \mathrm{Cl}_{2}$ (100 $\mathrm{mL} \times$ four times). The organic layer was dried over anhydrous $\mathrm{MgSO}_{4}$ and concentrated. Silica gel column chromatography was performed while increasing the polarity of the eluents from $\mathrm{CH}_{2} \mathrm{Cl}_{2}: n$-hexane $=1: 2(\mathrm{v} / \mathrm{v})$ to $\mathrm{CH}_{2} \mathrm{Cl}_{2}: n$-hexane $=1: 1(\mathrm{v} / \mathrm{v})$ to furnish a yellow powder in a $52 \%$ yield. ${ }^{1} \mathrm{H}$ NMR $\left(300 \mathrm{MHz}, \mathrm{CDCl}_{3}\right) \delta: 6.44(\mathrm{~d}, J=9.5 \mathrm{~Hz}, 1 \mathrm{H})$, 7.42-7.56 (m, 6H), 7.62-7.65 (m, 2H), 7.75 (d, $J=9.5 \mathrm{~Hz}, 1 \mathrm{H})$. ${ }^{13} \mathrm{C}$ NMR $\left(126 \mathrm{MHz}, \mathrm{CDCl}_{3}\right) \delta: 115.26,116.54,118.02,123.53$, $127.43,128.33,128.75,129.29,139.38,143.25,145.29,154.73$, 161.01. HR MS $\left(\mathrm{FAB}^{+}, m\right.$-NBA): calcd for $\mathrm{C}_{15} \mathrm{H}_{10} \mathrm{O}_{2}\left([\mathrm{M}+\mathrm{H}]^{+}\right)$, 223.0759; found, 223.0765. Anal. calcd for $\mathrm{C}_{15} \mathrm{H}_{10} \mathrm{O}_{2}$ : C, 81.07; $\mathrm{H}$, 4.54. Found: C, 81.02; H, 4.51.

Synthesis of NC. The procedure used for the synthesis of PC was employed for the synthesis of NC, using 1-naphthylboronic acid in place of phenylboronic acid. A white solid (85\%) was obtained. ${ }^{1} \mathrm{H}$ NMR $\left(400 \mathrm{MHz}, \mathrm{CDCl}_{3}\right) \delta: 6.48(\mathrm{~d}, J=9.6 \mathrm{~Hz}, 1 \mathrm{H})$, $7.43-7.57(\mathrm{~m}, 6 \mathrm{H}), 7.60(\mathrm{~d}, J=8.0 \mathrm{~Hz}, 1 \mathrm{H}), 7.80(\mathrm{~d}, J=9.6 \mathrm{~Hz}$, $1 \mathrm{H}), 7.86(\mathrm{~d}, J=8.4 \mathrm{~Hz}, 1 \mathrm{H}), 7.93(\mathrm{t}, J=6.4 \mathrm{~Hz}, 2 \mathrm{H}) .{ }^{13} \mathrm{C} \mathrm{NMR}$ $\left(126 \mathrm{MHz}, \mathrm{CDCl}_{3}\right) \delta: 116.78,118.07,118.43,125.53,126.30$, 126.67, 126.76, 127.29, 127.79, 128.70, 128.85, 131.27, 134.03, 138.39, 143.34, 145.14, 154.27, 160.97. HR MS (FAB $\left.{ }^{+}, m-\mathrm{NBA}\right)$ : calcd for $\mathrm{C}_{19} \mathrm{H}_{12} \mathrm{O}_{2}\left([\mathrm{M}+\mathrm{H}]^{+}\right), 273.0916$; found, 273.0914. Anal. calcd for $\mathrm{C}_{19} \mathrm{H}_{12} \mathrm{O}_{2}$ : C, 83.81; $\mathrm{H}, 4.44$. Found: $\mathrm{C}, 83.81 ; \mathrm{H}, 4.44$.

Synthesis of AC. The identical procedure used for the synthesis of PC was employed for the synthesis of AC, using 9-anthrylboronic acid in place of phenylboronic acid. A yellow powder (28\%) was obtained. ${ }^{1} \mathrm{H}$ NMR $\left(300 \mathrm{MHz}, \mathrm{CDCl}_{3}\right)$ $\delta: 6.55(\mathrm{~d}, J=9.6 \mathrm{~Hz}, 1 \mathrm{H}), 7.35-7.41(\mathrm{~m}, 3 \mathrm{H}), 7.46-7.51(\mathrm{~m}, 3 \mathrm{H})$,
7.59-7.62 (m, 2H), $7.70(\mathrm{~d}, J=7.5 \mathrm{~Hz}, 1 \mathrm{H}), 7.88(\mathrm{~d}, J=9.6 \mathrm{~Hz}, 1 \mathrm{H})$, $8.08(\mathrm{~d}, J=8.4 \mathrm{~Hz}, 2 \mathrm{H}), 8.56(\mathrm{~s}, 1 \mathrm{H}) .{ }^{13} \mathrm{C} \mathrm{NMR}\left(126 \mathrm{MHz}, \mathrm{CDCl}_{3}\right)$ $\delta: 117.00,118.31,119.79,125.43,126.12,126.17,127.68,127.93$, 128.69, 129.96, 131.40, 134.62, 143.40, 143.44, 154.29, 160.87. HR MS (FAB ${ }^{+}, m$-NBA): calcd for $\mathrm{C}_{26} \mathrm{H}_{14} \mathrm{O}_{2}\left([\mathrm{M}+\mathrm{H}]^{+}\right), 323.1072$; found, 323.1072. Anal. calcd for $\mathrm{C}_{23} \mathrm{H}_{14} \mathrm{O}_{2}$ : C, 85.70; H, 4.38. Found: C, 85.70; H, 4.40.

\section{Characterization}

Steady-state UV-vis absorption measurements. UV-vis absorption spectra were collected using an Agilent, Cary 300 spectrophotometer at $298 \mathrm{~K} .10 \mu \mathrm{M}$ or $50 \mu \mathrm{M}$ solutions were freshly prepared prior to collecting the measurements. Polymer films were spin-coated onto $1 \mathrm{~cm} \times 1 \mathrm{~cm}$ quartz plates, using an EPLEX, SPIN-1200D spin coater. 1,2-Dichloroethane solutions containing $10 \mathrm{wt} \%$ PVK or PMMA and coumarin compounds (10 wt $\%$ relative to polymer) were sonicated for more than $30 \mathrm{~min}$. The polymer solutions were passed through a membrane filter (pore size $=8.0 \mu \mathrm{m}$ ) to remove insoluble particulates.

Steady-state photoluminescence measurements. Photoluminescence spectra were obtained using a PTI, Quanta Master 400 scanning spectrofluorimeter at $298 \mathrm{~K}$. The $10 \mu \mathrm{M}$ solutions or the polymer films containing $10 \mathrm{wt} \%$ dopants were used for the measurements. The relative photoluminescence quantum yields (PLQYs) of the solutions were determined according to the following standard equation: PLQY $=\mathrm{PLQY}_{\text {ref }} \times\left(I / I_{\text {ref }}\right) \times\left(A_{\text {ref }} / A\right) \times\left(n / n_{\text {ref }}\right)^{2}$, where $A, I$, and $n$ are the absorbance at the excitation wavelength, integrated photoluminescence intensity, and the refractive index of the solvent, respectively. 9,10-Diphenylanthracene in toluene solution was used as the external reference $\left(\mathrm{PLQY}_{\mathrm{ref}}=1.00\right) .{ }^{57}$ The PLQY values of the polymer films were determined by integrating over a sphere (PTI), according to the manufacturer's protocol.

Photoluminescence lifetime measurements. $50 \mu \mathrm{M}$ solutions in Ar-saturated cyclohexane and polymer films doped with $10 \mathrm{wt} \%$ coumarin compounds were used to determine the photoluminescence lifetimes of the coumarin compounds. Photoluminescence decay traces were acquired using time-correlated single-photon-counting (TCSPC) techniques using a PicoQuant, FluoTime 200 instrument after picosecond pulsed laser excitation. A $377 \mathrm{~nm}$ diode laser (PicoQuant, Germany) was used as the excitation source. The photoluminescence signals were collected through an automated motorized monochromator. Photoluminescence decay profiles were analyzed (OriginPro 8.0, OriginLab) using single or multi exponential decay models.

Cyclic voltammetry. Cyclic voltammograms of the deaerated $\mathrm{CH}_{3} \mathrm{CN}$ solutions ( $3 \mathrm{~mL}$ ) containing $2.0 \mathrm{mM}$ coumarin compounds and $0.10 \mathrm{M} \mathrm{TBAPF}_{6}$ supporting electrolyte were collected at $298 \mathrm{~K}$ using a CHI630B instrument ( $\mathrm{CH}$ Instruments). A conventional three-electrode cell was used with a platinum working electrode and a platinum wire as a counter electrode. The potentials were recorded with respect to the $\mathrm{Ag} / \mathrm{AgNO}$ $(0.010 \mathrm{M})$ pseudo reference electrode and were adjusted to the corresponding values against SCE by adding $0.29 \mathrm{~V}$. The scan rate was $0.10 \mathrm{~V} \mathrm{~s}^{-1}$.

Differential pulse voltammetry. Differential pulse voltammograms for the deaerated $\mathrm{CH}_{3} \mathrm{CN}$ solutions $(3 \mathrm{~mL})$ containing 
$2.0 \mathrm{mM}$ coumarin compounds and $0.10 \mathrm{M} \mathrm{TBAPF}_{6}$ supporting electrolyte were obtained at $298 \mathrm{~K}$ using a CHI630B instrument (CH Instruments). A conventional three-electrode cell was used with a platinum working electrode and a platinum wire as a counter electrode. The potentials were recorded with respect to the $\mathrm{Ag} / \mathrm{AgNO}_{3}(0.010 \mathrm{M})$ pseudo reference electrode and were adjusted to the corresponding values against SCE by adding $0.29 \mathrm{~V}$. The scan rate was $4.0 \mathrm{mV} \mathrm{s}^{-1}$.

DFT/TD-DFT calculations. Quantum chemical calculations based on density functional theory (DFT) were carried out using the Gaussian 09 program. ${ }^{104}$ Geometry optimization and single point calculations of the model structures were performed using the long range corrected version of B3LYP using the Coulomb-attenuating method (CAM-B3LYP) and the 6-311+G(d,p) basis set. The polarizable continuum model (CPCM), parameterized for THF, was applied during the geometry optimization step. Frequency calculations were subsequently performed to assess the stability of the convergence. The TD-DFT calculations were applied to the optimized geometries using the same functionals and basis sets that were used for geometry optimization. The polarizable continuum model (CPCM) parameterized for THF was applied to account for solvation effects. The twenty lowest singlet and triplet states were calculated and analyzed.

Femtosecond laser flash photolysis. Femtosecond transient absorption spectroscopy experiments were conducted using an ultrafast source, Integra-C (Quantronix Corp.), an optical parametric amplifier, TOPAS (Light Conversion Ltd), and a commercially available optical detection system, Helios, provided by Ultrafast Systems LLC. The source of the pump and probe pulses was the fundamental output of Integra-C (780 nm, $2 \mathrm{~mJ}$ per pulse and FWHM = $130 \mathrm{fs}$ ) at a repetition rate of $1 \mathrm{kHz}$. A $75 \%$ portion of the fundamental output of the laser was introduced into TOPAS, which includes optical frequency mixers that can tune the output over the range 285-1660 $\mathrm{nm}$. The rest of the output was used to generate white light. Prior to generating the probe continuum, a variable neutral density filter was inserted into the path to obtain a stable continuum, and the laser pulse was fed to a delay line that provided an experimental time window of $3.2 \mathrm{~ns}$ with a maximum step resolution of $7 \mathrm{fs}$. An excitation wavelength of $350 \mathrm{~nm}$ in the TOPAS output was selected as the pump beam. Because this TOPAS output consisted of the desired wavelength as well as the other unnecessary wavelengths, the latter were deflected using a wedge prism with a wedge angle of $18^{\circ}$. The desired beam was used to irradiate the sample film with a spot size of $1 \mathrm{~mm}$ diameter. The beam merged with the white probe pulse at small angles $\left(<10^{\circ}\right)$. After passing through the film, the probe beam was focused onto a fiber optic cable connected to a CCD spectrograph to record the time-resolved spectra (470-800 nm). Typically, 3000 excitation pulses were averaged over $3 \mathrm{~s}$ to obtain the transient spectrum at a set delay time. Kinetic traces at appropriate wavelengths were assembled from the timeresolved spectral data. All measurements were conducted at room temperature, $298 \mathrm{~K}$.

\section{Acknowledgements}

This research was supported by a grant from the Samsung Research Funding Center for Future Technology (SRFCMA1301-01 to Y. Y.).

\section{Notes and references}

1 R. O'Kennedy and R. D. Thornes, Coumarins: Biology, Applications and Mode of Actions, Wiley, Chichester, 1997.

2 M. Tasior, D. Kim, S. Singha, M. Krzeszewski, K. H. Ahn and D. T. Gryko, J. Mater. Chem. C, 2015, 3, 1421-1446.

3 J. S. Seixas de Melo, R. S. Becker and A. L. Macanita, J. Phys. Chem., 1994, 98, 6054-6058.

4 T. Wolff and H. Goerner, Phys. Chem. Chem. Phys., 2004, 6, 368-376.

5 J. Seixas de Melo, R. S. Becker, F. Elisei and A. L. Macanita, J. Chem. Phys., 1997, 107, 6062-6069.

6 M. A. El-Sayed, J. Chem. Phys., 1962, 36, 573-574.

7 C. M. Krauter, J. Moehring, T. Buckup, M. Pernpointner and M. Motzkus, Phys. Chem. Chem. Phys., 2013, 15, 17846-17861. 8 P. A. Vadola and D. Sames, J. Org. Chem., 2012, 77, 7804-7814.

9 E. Soleimani, M. M. Khodaei, N. Batooie and S. Samadi, J. Heterocycl. Chem., 2012, 49, 409-412.

10 X.-G. Liu, S.-S. Zhang, C.-Y. Jiang, J.-Q. Wu, Q. Li and H. Wang, Org. Lett., 2015, 17, 5404-5407.

11 N. Sepay, C. Guha, A. Kool and A. K. Mallik, RSC Adv., 2015, 5, 70718-70725.

12 S. Yaragorla, A. Pareek and R. Dada, Tetrahedron Lett., 2015, 56, 4770-4774.

13 L. Calmus, A. Corbu and J. Cossy, Adv. Synth. Catal., 2015, 357, 1381-1386.

14 Y. Yang, J. Han, X. Wu, S. Xu and L. Wang, Tetrahedron Lett., 2015, 56, 3809-3812.

15 S. K. Gadakh, S. Dey and A. Sudalai, J. Org. Chem., 2015, 80, 11544-11550.

16 C. R. Sinu, D. V. M. Padmaja, U. P. Ranjini, K. C. Seetha Lakshmi, E. Suresh and V. Nair, Org. Lett., 2013, 15, 68-71.

17 K. Li, Y. Zeng, B. Neuenswander and J. A. Tunge, J. Org. Chem., 2005, 70, 6515-6518.

18 D. C. Dittmer, Q. Li and D. V. Avilov, J. Org. Chem., 2005, 70, 4682-4686.

19 J. Donovalova, M. Cigan, H. Stankovicova, J. Gaspar, M. Danko, A. Gaplovsky and P. Hrdlovic, Molecules, 2012, 17, 3259-3276.

20 A. C. Morteani, P. Sreearunothai, L. M. Herz, R. H. Friend and C. Silva, Phys. Rev. Lett., 2004, 92, 247402.

21 M. Lor, J. Thielemans, L. Viaene, M. Cotlet, J. Hofkens, T. Weil, C. Hampel, K. Müllen, J. W. Verhoeven, M. V. d. Auweraer and F. C. D. Schryver, J. Am. Chem. Soc., 2002, 124, 9918-9925.

22 A. Weller, in The Exciplex, ed. M. Gordon and W. R. Ware, 1975, ch. 23.

23 A. C. Morteani, A. S. Dhoot, J.-s. Kim, C. Silva, N. C. Greenham, C. Murphy, E. Moons, S. Cina, J. H. Burroughes and R. H. Friend, Adv. Mater., 2003, 15, 1708-1712. 
24 S. A. Jenekhe and J. A. Osaheni, Science, 1994, 265, 765-768. 25 X. Zhang, D. M. Kale and S. A. Jenekhe, Macromolecules, 2002, 35, 382-393.

26 M. M. Alam and S. A. Jenekhe, J. Phys. Chem. B, 2001, 105, 2479-2482.

27 T. Offermans, P. A. van Hal, S. C. J. Meskers, M. M. Koetse and R. A. J. Janssen, Phys. Rev. B: Condens. Matter Mater. Phys., 2005, 72, 045213.

28 C. Yin, T. Kietzke, D. Neher and H.-H. Horhold, Appl. Phys. Lett., 2007, 90, 092117.

29 H. Sakai, A. Itaya and H. Masuhara, J. Phys. Chem., 1989, 93, 5351-5353.

30 V. Cherpak, P. Stakhira, B. Minaev, G. Baryshnikov, E. Stromylo, I. Helzhynskyy, M. Chapran, D. Volyniuk, Z. Hotra, A. Dabuliene, A. Tomkeviciene, L. Voznyak and J. V. Grazulevicius, ACS Appl. Mater. Interfaces, 2015, 7, 1219-1225.

31 J. H. Kim, B.-K. An, S.-J. Yoon, S. K. Park, J. E. Kwon, C.-K. Lim and S. Y. Park, Adv. Funct. Mater., 2014, 24, 2746-2753.

32 T. Granlund, L. A. A. Pettersson, M. R. Anderson and O. Inganas, J. Appl. Phys., 1997, 81, 8097-8103.

33 J. F. Wang, Y. Kawabe, S. E. Shaheen, M. M. Morrell, G. E. Jabbour, P. A. Lee, J. Anderson, N. R. Armstrong, B. Kippelen, E. A. Mash and N. Peyghambarian, Adv. Mater., 1998, 10, 230-233.

34 S. L. Lai, M. Y. Chan, Q. X. Tong, M. K. Fung, P. F. Wang, C. S. Lee and S. T. Lee, Appl. Phys. Lett., 2008, 93, 143301.

35 R. M. Siegoczynski and W. Ejchart, Macromol. Symp., 2004, 212, 575-580.

36 K.-H. Kim, C.-K. Moon, J. W. Sun, B. Sim and J.-J. Kim, Adv. Opt. Mater., 2015, 3, 895-899.

37 J. W. Sun, J. Y. Baek, K.-H. Kim, C.-K. Moon, J.-H. Lee, S.-K. Kwon, Y.-H. Kim and J.-J. Kim, Chem. Mater., 2015, 27, 6675-6681.

38 G. Li, C. H. Kim, Z. Zhou, J. Shinar, K. Okumoto and Y. Shirota, Appl. Phys. Lett., 2006, 88, 253505.

39 T. Zhang, B. Zhao, B. Chu, W. Li, Z. Su, X. Yan, C. Liu, H. Wu, Y. Gao, F. Jin and F. Hou, Sci. Rep., 2015, 5, 10234.

40 T. Zhang, B. Chu, W. Li, Z. Su, Q. M. Peng, B. Zhao, Y. Luo, F. Jin, X. Yan, Y. Gao, H. Wu, F. Zhang, D. Fan and J. Wang, ACS Appl. Mater. Interfaces, 2014, 6, 11907-11914.

41 Y.-S. Park, K.-H. Kim and J.-J. Kim, Appl. Phys. Lett., 2013, 102, 153306.

42 X.-K. Liu, Z. Chen, C.-J. Zheng, C.-L. Liu, C.-S. Lee, F. Li, X.-M. Ou and X.-H. Zhang, Adv. Mater., 2015, 27, 2378-2383.

43 X.-K. Liu, Z. Chen, C.-J. Zheng, M. Chen, W. Liu, X.-H. Zhang and C.-S. Lee, Adv. Mater., 2015, 27, 2025-2030.

44 X.-K. Liu, Z. Chen, J. Qing, W.-J. Zhang, B. Wu, H. L. Tam, F. Zhu, X.-H. Zhang and C.-S. Lee, Adv. Mater., 2015, 27, 7079-7085.

$45 \mathrm{~J}$. Li, H. Nomura, H. Miyazaki and C. Adachi, Chem. Commun., 2014, 50, 6174-6176.

46 A. P. Kulkarni and S. A. Jenekhe, J. Phys. Chem. C, 2008, 112, 5174-5184.

47 K. Goushi, K. Yoshida, K. Sato and C. Adachi, Nat. Photonics, 2012, 6, 253-258.
48 K. Goushi and C. Adachi, Appl. Phys. Lett., 2012, 101, 023306.

49 D. Chen, Z. Wang, D. Wang, Y.-C. Wu, C.-C. Lo, A. Lien, Y. Cao and S.-J. Su, Org. Electron., 2015, 25, 79-84.

50 Z. Chen, X.-K. Liu, C.-J. Zheng, J. Ye, C.-L. Liu, F. Li, X.-M. Ou, C.-S. Lee and X.-H. Zhang, Chem. Mater., 2015, 27, 5206-5211.

51 V. Jankus, P. Data, D. Graves, C. McGuinness, J. Santos, M. R. Bryce, F. B. Dias and A. P. Monkman, Adv. Funct. Mater., 2014, 24, 6178-6186.

52 Y. O. Lee, J. Y. Lee, D. T. Quang, M. H. Lee and J. S. Kim, Bull. Korean Chem. Soc., 2006, 27, 1469-1472.

53 K. H. Ibnaouf, S. Prasad, A. S. Aldwayyan, M. S. Al Salhi and V. Masilamani, Spectrochim. Acta, Part A, 2012, 97, 1145-1151.

54 V. Masilamani and A. S. Aldwayyan, Spectrochim. Acta, Part A, 2004, 60, 2099-2106.

55 H. N. Ghosh, J. Phys. Chem. B, 1999, 103, 10382-10387.

56 A. Furube, R. Katoh, T. Yoshihara, K. Hara, S. Murata, H. Arakawa and M. Tachiya, J. Phys. Chem. B, 2004, 108, 12583-12592.

57 G. Heinrich, S. Schoof and H. Gusten, J. Photochem., 1974, 3, 315-320.

58 The glass transition temperature of PMMA (105 C) was significantly higher than the room temperature, effectively prohibiting intramolecular motions of the coumarin compounds.

59 Y. Tsujii, A. Tsuchida, M. Yamamoto and Y. Nishijima, Macromolecules, 1988, 21, 665-670.

60 J. J. Benson-Smith, J. Wilson, C. Dyer-Smith, K. Mouri, S. Yamaguchi, H. Murata and J. Nelson, J. Phys. Chem. B, 2009, 113, 7794-7799.

61 C. Dyer-Smith, J. J. Benson-Smith, D. D. C. Bradley, H. Murata, W. J. Mitchell, S. E. Shaheen, S. A. Haque and J. Nelson, J. Phys. Chem. C, 2009, 113, 14533-14539.

62 Y. Tsujii, A. Tsuchida, Y. Onogi and M. Yamamoto, Macromolecules, 1990, 23, 4019-4023.

63 M. Murakami, K. Ohkubo, T. Nanjo, K. Souma, N. Suzuki and S. Fukuzumi, ChemPhysChem, 2010, 11, 2594-2605.

64 D. R. Worrall, S. L. Williams, F. Wilkinson, J. E. Crossley, H. Bouas-Laurent and J.-P. Desvergne, J. Phys. Chem. B, 1999, 103, 9255-9261.

65 D. R. Worrall, S. L. Williams and F. Wilkinson, J. Phys. Chem. B, 1997, 101, 4709-4716.

66 S. Fukuzumi, T. Okamoto and K. Ohkubo, J. Phys. Chem. A, 2003, 107, 5412-5418.

67 S. Fukuzumi, I. Nakanishi and K. Tanaka, J. Phys. Chem. A, 1999, 103, 11212-11220.

68 M. Fujitsuka, Y. Yahata, A. Watanabe and O. Ito, Polymer, 2000, 41, 2807-2812.

69 G. W. Haggquist and R. D. Burkhart, Macromolecules, 1995, 28, 2465-2471.

70 G. W. Haggquist, R. D. Burkhart and K. R. Naqvi, J. Phys. Chem., 1991, 95, 7588-7594.

71 X.-L. Chen, R. Yu, Q.-K. Zhang, L.-J. Zhou, X.-Y. Wu, Q. Zhang and C.-Z. Lu, Chem. Mater., 2013, 25, 3910-3920.

72 R. Czerwieniec, J.-B. Yu and H. Yersin, Inorg. Chem., 2011, 50, 8293-8301. 
73 J. C. Deaton, S. C. Switalski, D. Y. Kondakov, R. H. Young, T. D. Pawlik, D. J. Giesen, S. B. Harkins, A. J. M. Miller, S. F. Mickenberg and J. C. Peters, J. Am. Chem. Soc., 2010, 132, 9499-9508.

74 T. Gneuß, M. J. Leitl, L. H. Finger, N. Rau, H. Yersin and J. Sundermeyer, Dalton Trans., 2015, 44, 8506-8520.

75 T. Hofbeck, U. Monkowius and H. Yersin, J. Am. Chem. Soc., 2015, 137, 399-404.

76 S. Igawa, M. Hashimoto, I. Kawata, M. Yashima, M. Hoshino and M. Osawa, J. Mater. Chem. C, 2013, 1, 542-551.

77 M. J. Leitl, V. A. Krylova, P. I. Djurovich, M. E. Thompson and H. Yersin, J. Am. Chem. Soc., 2014, 136, 16032-16038.

78 M. Osawa, Chem. Commun., 2014, 50, 1801-1803.

79 M. Osawa, M. Hoshino, M. Hashimoto, I. Kawata, S. Igawa and M. Yashima, Dalton Trans., 2015, 44, 8369-8378.

80 A. Tsuboyama, K. Kuge, M. Furugori, S. Okada, M. Hoshino and K. Ueno, Inorg. Chem., 2007, 46, 1992-2001.

81 H. Yersin, A. F. Rausch, R. Czerwieniec, T. Hofbeck and T. Fischer, Coord. Chem. Rev., 2011, 255, 2622-2652.

82 D. M. Zink, M. Bächle, T. Baumann, M. Nieger, M. Kühn, C. Wang, W. Klopper, U. Monkowius, T. Hofbeck, H. Yersin and S. Bräse, Inorg. Chem., 2013, 52, 2292-2305.

83 D. M. Zink, T. Grab, T. Baumann, M. Nieger, E. C. Barnes, W. Klopper and S. Bräse, Organometallics, 2011, 30, 3275-3283.

84 A. Endo, K. Sato, K. Yoshimura, T. Kai, A. Kawada, H. Miyazaki and C. Adachi, Appl. Phys. Lett., 2011, 98, 083302.

85 H. Hirai, K. Nakajima, S. Nakatsuka, K. Shiren, J. Ni, S. Nomura, T. Ikuta and T. Hatakeyama, Angew. Chem., Int. Ed., 2015, 54, 13581-13585.

86 S. Hirata, Y. Sakai, K. Masui, H. Tanaka, S. Y. Lee, H. Nomura, N. Nakamura, M. Yasumatsu, H. Nakanotani, Q. Zhang, K. Shizu, H. Miyazaki and C. Adachi, Nat. Mater., 2015, 14, 330-336.

87 H. Kaji, H. Suzuki, T. Fukushima, K. Shizu, K. Suzuki, S. Kubo, T. Komino, H. Oiwa, F. Suzuki, A. Wakamiya, Y. Murata and C. Adachi, Nat. Commun., 2015, 6, 8476.

88 M. Kim, S. K. Jeon, S.-H. Hwang and J. Y. Lee, Adv. Mater., 2015, 27, 2515-2520.

89 Y. Kitamoto, T. Namikawa, D. Ikemizu, Y. Miyata, T. Suzuki, H. Kita, T. Sato and S. Oi, J. Mater. Chem. C, 2015, 3, 9122-9130.

90 D. R. Lee, S.-H. Hwang, S. K. Jeon, C. W. Lee and J. Y. Lee, Chem. Commun., 2015, 51, 8105-8107.

91 J. Lee, K. Shizu, H. Tanaka, H. Nakanotani, T. Yasuda, H. Kaji and C. Adachi, J. Mater. Chem. C, 2015, 3, 2175-2181.
92 S. Y. Lee, T. Yasuda, I. S. Park and C. Adachi, Dalton Trans., 2015, 44, 8356-8359.

93 G. Mehes, H. Nomura, Q. Zhang, T. Nakagawa and C. Adachi, Angew. Chem., Int. Ed., 2012, 51, 11311-11315.

94 T. Nakagawa, S.-Y. Ku, K.-T. Wong and C. Adachi, Chem. Commun., 2012, 48, 9580-9582.

95 M. Numata, T. Yasuda and C. Adachi, Chem. Commun., 2015, 51, 9443-9446.

96 Y. Sakai, Y. Sagara, H. Nomura, N. Nakamura, Y. Suzuki, H. Miyazaki and C. Adachi, Chem. Commun., 2015, 51, 3181-3184.

97 K. Sato, K. Shizu, K. Yoshimura, A. Kawada, H. Miyazaki and C. Adachi, Phys. Rev. Lett., 2013, 110, 247401.

98 K. Shizu, H. Noda, H. Tanaka, M. Taneda, M. Uejima, T. Sato, K. Tanaka, H. Kaji and C. Adachi, J. Phys. Chem. C, 2015, 119, 26283-26289.

99 K. Suzuki, S. Kubo, K. Shizu, T. Fukushima, A. Wakamiya, Y. Murata, C. Adachi and H. Kaji, Angew. Chem., Int. Ed., 2015, 54, 15231-15235.

100 H. Tanaka, K. Shizu, J. Lee and C. Adachi, J. Phys. Chem. C, 2015, 119, 2948-2955.

101 H. Tanaka, K. Shizu, H. Miyazaki and C. Adachi, Chem. Commun., 2012, 48, 11392-11394.

102 M. Taneda, K. Shizu, H. Tanaka and C. Adachi, Chem. Commun., 2015, 51, 5028-5031.

103 H. Uoyama, K. Goushi, K. Shizu, H. Nomura and C. Adachi, Nature, 2012, 492, 234-238.

104 M. J. Frisch, G. W. Trucks, H. B. Schlegel, G. E. Scuseria, M. A. Robb, J. R. Cheeseman, G. Scalmani, V. Barone, B. Mennucci, G. A. Petersson, H. Nakatsuji, M. Caricato, X. Li, H. P. Hratchian, A. F. Izmaylov, J. Bloino, G. Zheng, J. L. Sonnenberg, M. Hada, M. Ehara, K. Toyota, R. Fukuda, J. Hasegawa, M. Ishida, T. Nakajima, Y. Honda, O. Kitao, H. Nakai, T. Vreven, J. A. Montgomery, Jr., J. E. Peralta, F. Ogliaro, M. Bearpark, J. J. Heyd, E. Brothers, K. N. Kudin, V. N. Staroverov, T. Keith, R. Kobayashi, J. Normand, K. Raghavachari, A. Rendell, J. C. Burant, S. S. Iyengar, J. Tomasi, M. Cossi, N. Rega, J. M. Millam, M. Klene, J. E. Knox, J. B. Cross, V. Bakken, C. Adamo, J. Jaramillo, R. Gomperts, R. E. Stratmann, O. Yazyev, A. J. Austin, R. Cammi, C. Pomelli, J. W. Ochterski, R. L. Martin, K. Morokuma, V. G. Zakrzewski, G. A. Voth, P. Salvador, J. J. Dannenberg, S. Dapprich, A. D. Daniels, O. Farkas, J. B. Foresman, J. V. Ortiz, J. Cioslowski and D. J. Fox, Gaussian, Inc., Wallingford CT, 2013. 